\author{
UNIVERSIDADE DE SÃO PAULO \\ Faculdade de Medicina de Ribeirão Preto \\ PÓS-GRADUAÇÃO EM IMUNOLOGIA BÁSICA E APLICADA
}

PAPEL DA ENZIMA 6-FOSFOFRUTO-2-QUINASE / FRUTOSE-2,6-BIFOSFATASE (PFKFB3) EM CÉLULAS T REGULADORAS

MARCOS HENRIQUe ROSA 


\author{
RIBEIRÃo PRETO \\ 2019 \\ UNIVERSIDADE DE SÃO PAULO \\ Faculdade de Medicina de Ribeirão Preto \\ PÓS-GRADUAÇÃo EM IMUNOLOGIA BÁSICA E APLICADA
}

\title{
PAPEL DA ENZIMA 6-FOSFOFRUTO-2-QUINASE / FRUTOSE-2,6-BIFOSFATASE (PFKFB3) EM CÉLULAS T REGULADORAS
}

MARCOS HENRIQUE ROSA

DISSERTAÇÃO APRESENTADA AO PROGRAMA DE PÓS-GRADUAÇÃO em IMUNOlogia Básica e Aplicada da Faculdade de Medicina de Ribeirão Preto da Universidade de São Paulo para obtençÃo do título de Mestre em CiÊncias, na ÁREA de CONCENTRAÇÃO: IMUNOLOGIA BÁSICA E APLICADA.

Orientador: Prof. Dr. José Carlos Farias Alves Filho 
Ribeirão Preto

2019

Autorizo A REPRODUÇÃO E DIVULGAÇÃO TOTAL OU PARCIAL DESTE TRABALHO, POR QUALQUER MEIO CONVENCIONAL OU ELETRÔNICO, PARA FINS DE ESTUDO E PESQUISA, DESDE QUE CITADA A FONTE.

Rosa, Marcos Henrique

Papel da enzima 6-fosfofruto-2-quinase / frutose-2,6-bifosfatase (PFKFB3) em células T reguladoras, 2019.64p.

Dissertação apresentada ao programa de pós-graduação em Imunologia Básica e Aplicada da Faculdade de Medicina de Ribeirão Preto da Universidade de São Paulo para obtenção do título de Mestre em Ciências, na área de concentração: Imunologia Básica e Aplicada.

Orientador: Prof. Dr. José Carlos Farias Alves Filho.

1.Célula T Reguladora. 2. Imunometabolismo. 3. PFKFB3. 
PAPEL DA ENZIMA 6-FOSFOFRUTO-2-QUINASE / FRUTOSE-2,6-BIFOSFATASE (PFKFB3) EM CÉLULAS T REGULADORAS

DISSERTAÇÃO APRESENTADA AO PROGRAMA DE PÓS-GRADUAÇÃO EM ImUnologia BÁsica e Aplicada da Faculdade de Medicina de Ribeirão Preto da Universidade de São Paulo para obtenção do título de Mestre em CiÊnCIAS, NA ÁREA de CONCENTRAÇÃo: IMUNOLOGIA BÁSICA E APLICADA.

APROVADO EM: $\mathrm{DE}$ DE

BANCA EXAMINADORA

Prof. Dr. José Carlos Farias AlVes Filho

Faculdade de Medicina de Ribeirão Preto

Prof. Dr. PaUlo Louzada JUNIOR

Faculdade de Medicina de Ribeirão Preto

Prof. Dr. JoÃo PaUlo de Biaso Viola

UNIVERSIDADE (OUTRA) 
DEDICO ESSE TRABALHO A MINHA FAMÍLIA E AMIGOS. 


\section{AGRADECIMENTOS}

Agradeço ao Professor Dr. José Carlos Farias Alves Filho profissional e pessoa exemplar, pela orientação, pelos valiosos ensinamentos que contribuíram para o meu crescimento científico, intelectual e pessoal.

Aos demais Professores do Laboratório de Inflamação e Dor, Prof. Dr. Thiago Mattar Cunha, e Prof. Dr. Fernando de Queiroz Cunha, pelas contribuições científicas e ensinamentos que contribuíram para o meu crescimento científico.

Agradeço aos Professores, Dr.João Biaso de Viola; e Dra. Maria Carolina de Oliverira de Rodrigues; pela disponibilidade de participar desta banca examinadora, que será de grande valia para as discussões e aperfeiçoamento deste trabalho.

Aos meus pais Rosalina da Silva Rosa e Vitor Rosa, pelo amor e carinho incondicional, pelos ensinamentos e exemplos os quais me definiram. Obrigado por estarem presentes nos momentos difíceis, me ajudando; e nos felizes, celebrando. Agradeço toda minha família.

Aos colegas do Laboratório de Inflamação e Dor, um laboratório fenomenal e fascinante, pois sempre obtive apoio científico e metodológico quando precisei. Agradeço pelas discussões científicas sobre esse trabalho, momentos de diálogo e aprendizado, e também pelos momentos de descontração (obs: fiquei com medo de escrever o nome de todos e esquecer de alguém, seria uma injustiça).

Aos técnicos Serginho, Diva, leda, Juliana, Marcela e Katinha pela amizade, suporte técnico, carinho e disponibilidade. Minha imensa admiração por manterem organizado um laboratório desse porte. Ainda, à Denise, pelo apoio nas longas separações de células na facility de citometria da FMRP, e pelos treinamentos operacionais. À Ana Cristine, pelo auxílio burocrático, obrigado. 
Obrigado aos meus amigos mais próximos, que diretamente ou indiretamente participaram desse trabalho e da minha formação, lá vai ... Douglas Prado (Hétero), Eduarda Damascena (Bixa), Daniele (Dany Crazy), Juliana dos Cigarros, Gabriel Públio, Thaina Norbiato e Flavio Protassio, pessoas chaves na minha formação pessoal e acadêmica. Carlos Hiroji Hiroki, Amanda Cristina Corveloni, Mikhael Haruo, Felipe Campos e Guilherme Martelossi Cebinelli meus amigos da UEL obrigado por esses 6 anos de amizade, desde a época da graduação. Agradecer também todo mundo deste laboratório por ser essa família unida e amorosa.

Agradecer também amigos que mesmo estando distantes, se tornaram presentes todos os dias, graças às novas tecnologias: Adriano Oliva, Alda Luis, Antônia Mello, Bruna Dias, Daniel Macedo, Dylon Gomes, Drusila Ferraioli Velloso, Érico de Paula, Gabriel Salomão, Gustavo Henrique Cardoso, Henrique Okuti Rick, Nazek Flausino, Otavio Abreu, Paulo Furukawa, Priscilla Jordão, Reinaldo Celso De Melo, Renato de Souza, Tibor Zequini, Vitor Uekawa e Wesley Daflita, Erica Romão, Silvia Ortigoza, Sabrina Feiticeira.

Às agências de fomento, Coordenação de Aperfeiçoamento Pessoal de Nível Superior (CAPES), Conselho Nacional de Desenvolvimento Tecnológico e Científico (CNPQ), Fundação de Amparo à Pesquisa do Estado de São Paulo (FAPESP) e ao Centerfor Research in Inflammatory Diseases (CRID) pelo apoio financeiro fundamental para desenvolvimento deste trabalho e concessão de bolsa de estudo (CNPq) e FAPESP.

E a todos, que direta ou indiretamente, contribuíram para meu crescimento pessoal e profissional e para a realização deste trabalho.

\section{O meu muito obrigado!}


"A verdadeira viagem de descobrimento não consiste em procurar novas paisagens, mas em ter novos olhos" (Marcel Proust) 


\section{Resumo}

Rosa, Marcos Henrique. Papel da enzima 6-Fosfofruto-2-Quinase / Frutose-2,6BIFOSFATASE (PFKFB3) EM CÉlULAS T REguladORAS. 2019. 64p. Dissertação (Mestrado em Imunologia Básica e Aplicada) - Faculdade de Medicina de Ribeirão Preto, Universidade de São Paulo, Ribeirão Preto, 2019.

\section{RESUMO}

Células $T$ reguladoras FoxP3+ (Tregs) desempenham funções supressoras cruciais para homeostase do sistema imunológico. Tem sido amplamente demonstrado que 0 metabolismo celular contribui efetivamente para proliferação, diferenciação e função das células do sistema imune, sendo a via glicolítica um importante ponto de integração de diferentes vias metabólicas. Nesse contexto, a enzima fosfofrutoquinase-1 (PFK-1), a qual catalisa a conversão da frutose 6-fosfato em frutose 1,6-bifosfato, atua em uma etapa limitante do fluxo glicolítico. A atividade da PFK-1 é regulada alostericamente pelo metabolito frutose-2,6-bifosfato (F2,6BP), o qual é produto da enzima 6-fosfofruto-2-quinase / frutose-2,6-bifosfatase 3 (PFKFB3). Sabe-se que a inibição da atividade cinase mediada pela PFKFB3 leva ao acumulo de intermediários da glicólise, os quais podem ser utilizados por outras vias metabólicas. Neste sentido, embora tenha sido descrito que o metabolismo oxidativo tenha um papel importante para o desenvolvimento e função de Tregs, resultados preliminares do nosso laboratório demonstraram que a via das hexosaminas possui papel importante na estabilidade e diferenciação de Tregs e a inibição da enzima PFKFB3 promove uma maior diferenciação de Tregs. Portanto, o presente trabalho visou compreender o papel da enzima PFKFB3 na diferenciação e função de Tregs, além disso verificou uma melhora dos sinais clínicos em camundongos tratados com inibidor da enzima PFKFB3 que demonstrou ser um possível alvo para o desenvolvimento de terapia para doenças inflamatórias.

Palavras-chave: PFKFB3. Autoimunidade. Linfócitos T Reguladores. Ativação 


\begin{abstract}
Rosa, Marcos Henrique. Role of enzYMe 6-PHOSPHOFRUCTO-2-KINASE / FRUCTOSE2,6-BISPHOSPHATASE 3 (PFKFB-3) IN REGULATORY T CELLS. 2019. 64p. Dissertation (Mestrado em Imunologia Básica e Aplicada) - Faculdade de Medicina de Ribeirão Preto, Universidade de São Paulo, Ribeirão Preto, 2019.

ABSTRACT

FoxP3 + regulatory T cells (Tregs) play crucial suppressive functions for homeostasis of immune system. It has been widely demonstrated that the cellular metabolism contributes effectively to the proliferation, differentiation and function of the cells of immune system, being the glycolytic pathway an important point of integration of different metabolic pathways. In light of this, the enzyme phosphofructokinase-1 (PFK1), which catalyzes the conversion of fructose 6-phosphate to fructose 1,6bisphosphate, acts in a limiting step of glycolytic flow. The activity of PFK-1 is regulated allosterically by the metabolite fructose-2,6-biphosphate (F2,6BP), which is a product of the enzyme 6-phosphofructo-2-kinase / fructose-2,6-bisphosphatase 3 (PFKFB3). It is well known that inhibition of the kinase activity of PFKFB3 may accumulate substrates for other important pathways of cellular metabolism. Although oxidative metabolism has been reported to play an important role in the development and function of Tregs, preliminary results from our laboratory have demonstrated that de hexosamines pathway is important to stability and differentiation of Treg and inhibition of the enzyme PFKFB3 promotes a greater differentiation of Tregs. Therefore, the present work aimed to understand the role of the enzyme PFKFB3 in the differentiation and function of Tregs, and verified an improvement of the clinical signs in mice treated with enzyme inhibitor PFKFB3 that proved to be a possible target for the development of therapy for inflammatory diseases.
\end{abstract}

Keywords: PFKFB3. Autoimmunity. Lymphocytes T Regulators. Activation. EAE. 


\section{LISTA DE ABREVIATURAS}

Treg - Célula T reguladora

Fox3 - Forkhead box P3

TCR - receptor de células $T$

TGF- $\beta$ Fator de transformação do crescimento beta

CTLA-4 cytotoxic $T$ lymphocyte antigen-4

GITR glucocorticoid-induced TNFR-family related receptor

PD-1 programmed death-1

ATP - Adenosina trifosfato

Glut - Transportador de glicose

PI3K - Akt dependente de fosfatidilinositol-3-cinase (PI3K)

mTOR - quinase alvo mamífero da rapamicina

GlcNAc - N-acetil-D-Glucosamina

GLUT - Glucose transporter

HIF-1a - Hypoxia-inducible factor

$\mathrm{Hk}$ - hexoquinase

i.p - intraperitoneal

IFN- - interferon gama

IL- interleucina

MHC - Major histocompatibity complex

OGA - O-GIcNAcase

OGT - O-GlcNAc transferase

Pdk1 - Piruvato desidrogenase quinase

Pfk - fosfofrutoquinase

PTEN - Phosphatase and tensin homolog

UAP1 - UDP-N-Acetylglucosamine Pyrophosphorylase 1

UDP-GlcNAc - Uridina difosfato N-acetil-D-glucosamina

AMP - Adenosina monofosfato

AMPK - Proteína quinase dependente de AMPK

F6P - Frutose-6-fosfato F6P

GFAT - Frutose-6P-amidotransferase

GNPNAT1 - glucosamina-6P Nacetiltransferase 
F1,6BP - Frutose 1,6-bifosfato

F2,6BP - Frutose2,6-bifosfato

PFK-1 - 6-fosfofrutoquinase-1 (PFK-1)

PFK-2 / FBPases - 6-fosfofruto-2-quinase/frutose-2,6-bifosfatases

PFKFB1 - 16 -fosfofruto-2-quinase/frutose-2,6-bifosfatase 1

PFKFB2 - 16 -fosfofruto-2-quinase/frutose-2,6-bifosfatase 2

PFKFB3 - 16 -fosfofruto-2-quinase/frutose-2,6-bifosfatase 3

PFKFB4 - 16 -fosfofruto-2-quinase/frutose-2,6-bifosfatase 4

EAE- Encefalomielite autoimune experimental

CFA - Adjuvante completo de Freud

SNC - Sistema nervoso central (SNC) 


\section{LISTA DE FIGURAS}

FIGURA 1 - METABOLISMO DE CÉLULAS T.

FIGURA 2 - VIA DAS HEXOAMINAS

FIGURA 3 - A) PFKFB3 E SUA FUNÇÃO NA VIA GLICOLÍTICA; B) POSSÍVEIS EFEITOS DA INIBICÃO DA ENZIMA EM CÉLULAS T REGULADORAS.

FIGURA 4 - EXPRESSÃ̃ GÊNICA DE PFKFB3 NOS ESTÁGIOS INICIAIS DE DIFERENCIAÇÃO DE CÉLULAS T REGULADORAS

FIGURA 5 - EXPRESSÃO PROTEICA DE PFKFB3 DURANTE A DIFERENCIAÇÃO DE LINFÓCITOS T REGULADORES

FIGURA 6 - EXPRESSÃO PROTEICA DE PFKFB3 DURANTE A DIFERENCIAÇÃO DE LINFÓCITOS T REGULADORES.

FIGURA 7 - A INIBIÇÃO DA ENZIMA PFKFB3 É CAPAZ DE GERAR MAIOR DIFERENCIAÇÃ̃O DE CÉLULAS T REGULADORAS

FIGURA 8 - A INIBIÇÃO DA ENZIMA PFKFB3 É CAPAZ DE GERAR MAIOR DIFERENCIAÇÃ̃O DE CÉLULAS T REGULADORAS E ESTE EFEITO É DEPENDENTE DO AUMENTO DE O-GLUCONALIZAÇÃO.

FIGURA 9 - A EXPRESSÃO DE PFKFB3 É AUMENTADA DURANTE O MODELO DE EAE

FIGURA 10 - TRATAMENTO COM INIBIDOR DE PFKFB3 É CAPAZ DE REDUZIR OS SINAIS CLÍNICOS DO MODELO DE EAE.

FIGURA 11 - O TRATAMENTO COM INIBIDOR DE 3PO É CAPAZ DE REDUZIR O INFILTRADO INFLAMATÓRIO E DEGRADAÇÃO DA MIELINA NO MODELO DE EAE.

FIGURA 12 - A DIFERENCIAÇÃO DE TREGS NÃO É AUMENTADA NOS LINFONODOS DE ANIMAIS TRATADOS COM INIBIDOR DE PFKFB3 NO $21^{\circ}$ DIA APÓS A INDUÇÃO DE EAE: 
INTRODUÇÃO

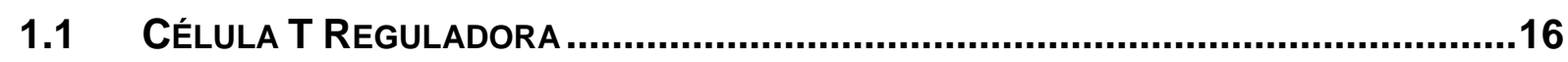

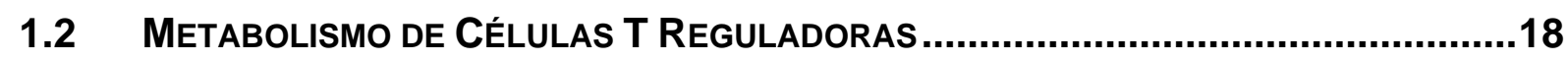

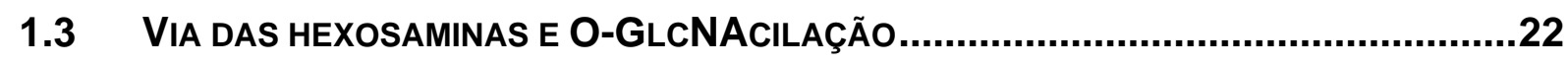

1.4 ENZIMA 6-FOSFOFRUTO-2-CINASE/FRUTOSE-2,6-BIFOSFATASE-3......................25

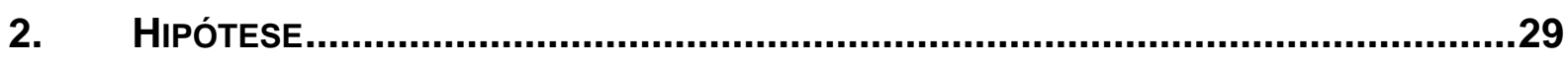

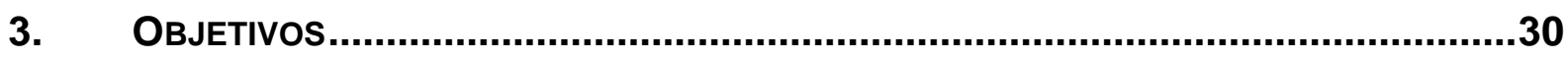

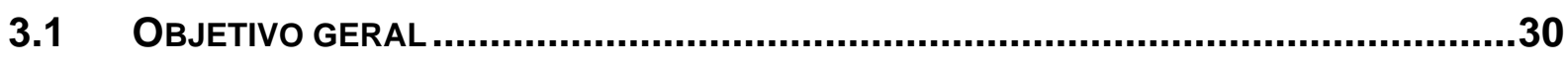

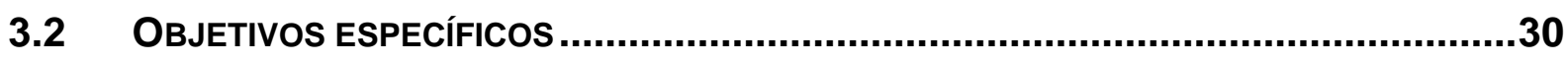

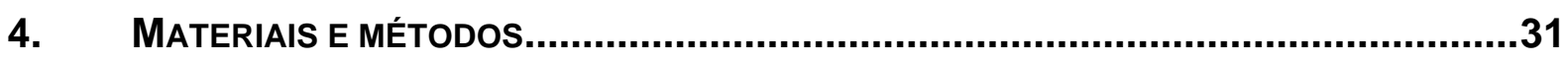

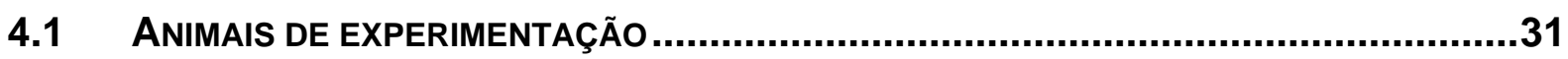

4.2 INDUÇÃO DA ENCEFALOMIELITE AUTOIMUNE EXPERIMENTAL ................................31

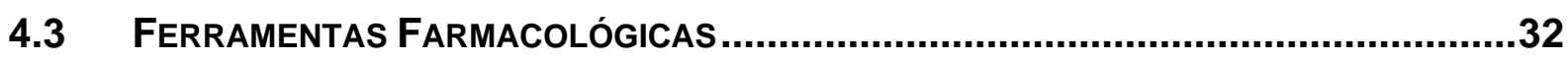

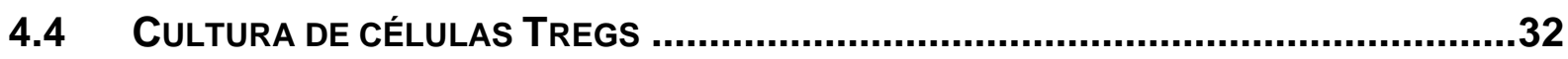

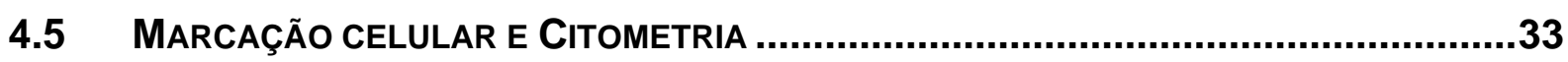

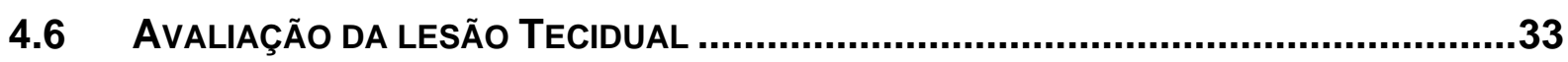

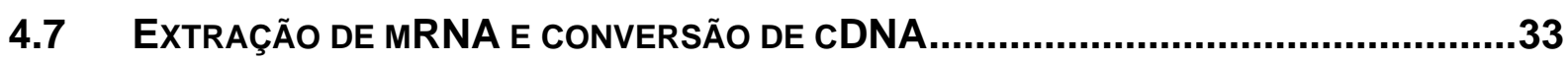

4.8 REAÇÃo EM CADEIA DA POLIMERASE QUANTITATIVA EM TEMPO REAL (RT-QPCR). 34

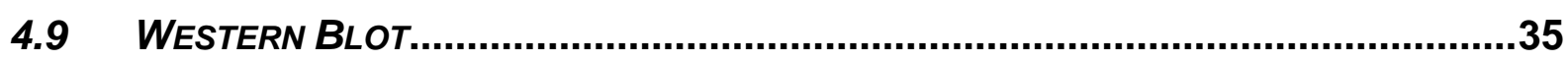

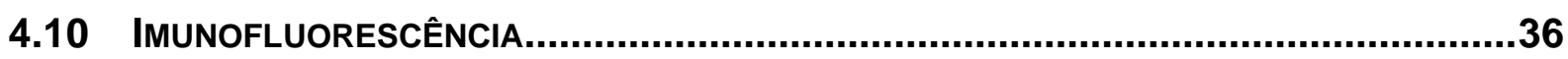

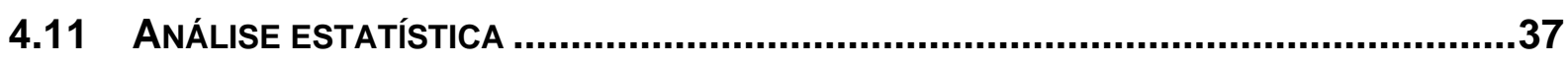

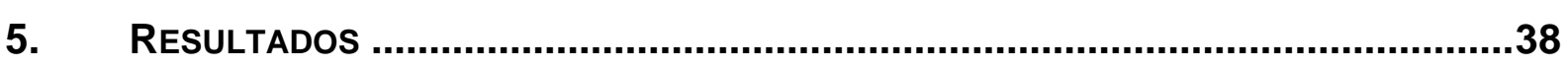

5.1 A ENZIMA PFKFB3 É EXPRESSA DURANTE A DIFERENCIAÇÃo dE CÉLULAS T

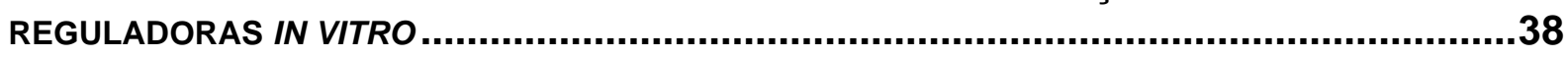

5.2 A INIBIÇÃo DA ENZIMA PFKFB3 EM CÉLULAS T REGULADORAS PODE GERAR ACÚMULOS DE PROTEÍNAS O-GLUCONACILADAS ...................................................41

5.3 A INIBIÇÃO DA ENZIMA PFKFB3 GERA AUMENTO NA DIFERENCIAÇÃO DE CÉLULAS T

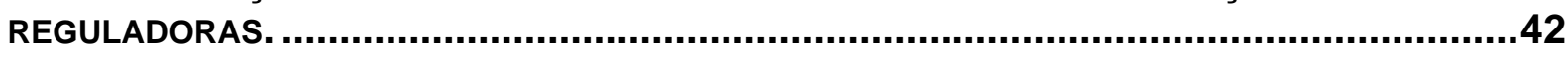

5.4 A EXPRESSÃo de PFKFB3 É AUMENTADA DURANTE O MODELO dE ENCEFALOMIELITE AUTOIMUNE EXPERIMENTAL. .45

5.5 O TRATAMENTO COM INIBIDOR DE PFKFB3 É CAPAZ DE REDUZIR OS SINAIS CLÍNICOS DO MODELO DE ENCEFALOMIELITE AUTOIMUNE EXPERIMENTAL 46 


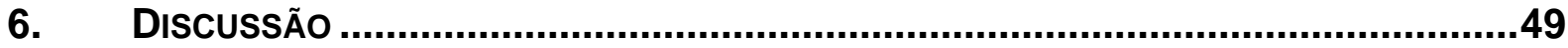

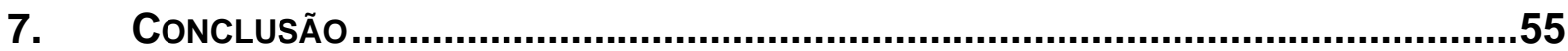

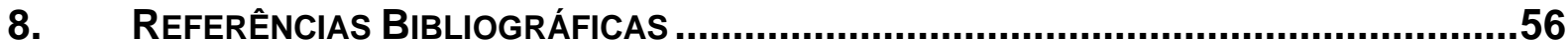

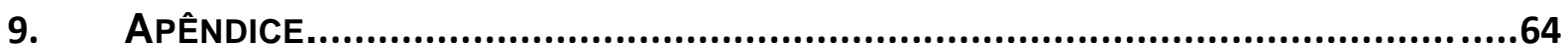




\section{INTRODUÇÃO}

\subsection{Célula T Reguladora}

Linfócitos T são células da imunidade adaptativa que possuem papéis diretos na eliminação de patógenos mas também possuem importantes funções auxiliares como a secreção de citocinas e fornecimento de sinais para amplificar ou iniciar respostas de outras células do sistema imune (Bonilla e Oettgen, 2010). Portanto, a tolerância dessas células T a antígenos próprios é essencial para a homeostase do sistema imune adaptativo, considerando seus papéis na montagem de uma resposta imunológica. Dentre os vários mecanismos para estabelecer e manter a auto tolerância, encontra-se as células $T$ reguladoras (Tregs) que são cruciais para as reações imunes contra os antígenos próprios e não próprios (Sakaguchi, 2000). Além disso, estudos vêm demonstrando que a função dessas células não se restringe apenas à prevenção da auto-imunidade, sendo importantes no controle de todas as formas de resposta imune nos contextos de inflamação, infecção, alergia, transplantes e imunidade tumoral (Hori e Sakaguchi, 2004).

As Tregs foram primeiramente caracterizadas com o fenótipo CD4+CD25high, sendo também verificada a importância das mesmas na prevenção da autoimunidade. Posteriormente a proteína FOXP3 (Forkhead box P3), um fator de transcrição necessário para a diferenciação, manutenção e função deste subtipo de linfócito foi identificado e aceito como um marcador de alta especificidade para essas células (Magenau et al., 2010). As Tregs são diferentes dos demais subtipos de células T CD4+ auxiliares, pois podem sofrer diferenciação durante o processo de maturação linfocitário que ocorre no timo, possuindo um papel central na auto tolerância. O TCR (receptor de células $\mathrm{T}$ ) dessa população de linfócitos é capaz de reconhecer auto 
antígenos graças as diversas interações com complexos MHC:antígeno-próprio no timo, durante o período de maturação (Li e Zheng, 2015). Além disso, células T que se encontram em órgãos periféricos podem converter-se em Tregs in vivo após sofrerem estimulação antigênica crônica ou em condições de linfopenia (Apostolou e Von Boehmer, 2004). Esse subtipo de Treg é pouco abundante em tecidos linfoides, no entanto, estão presentes em grandes quantidades em órgãos como placenta e intestino, estabelecendo tolerância à microorganismos comensais, alimentos, alérgenos e ao feto, pois possuem um TCR específico contra antígenos não patogênicos (Li e Zheng, 2015).

Assim como os demais subtipos de linfócitos, as Tregs também podem ser induzidas in vitro (iTregs) por uma combinação de estímulos: TGF- $\beta$ (Fator de transformação do crescimento beta) e IL-2 (Interleucina 2) associados à ativação do TCR (Anti-CD3 e Anti-CD28), os quais induzem a expressão de Foxp3 em células T naïve (Kanamori et al., 2016). As Tregs são conhecidas por serem extremante versáteis e com atividades imunossupressoras em diversos tecidos, apresentando uma série de funções que incluem: competição pela citocina IL-2 com linfócitos T efetores, supressão através de moléculas como CTLA-4 (cytotoxic T lymphocyte antigen-4); GITR (glucocorticoid-induced TNFR-family related receptor) e PD-1 (programmed death-1) (Sakaguchi, 2004); secreção de citocinas anti-inflamatórias (TGF- $\beta$, IL-10, IL-35) e morte mediada por granzima-B. (Nemazee, 2006; Sharma e Rudra, 2018). Além disso, as Tregs apresentam alta expressão de CD39/CD73, moléculas que reduzem a ativação de células T por converterem ATP em adenosina, diminuindo a energia célular (Bopp et al., 2007).

Para que Tregs consigam exercer sua função de manuntenção da homeostase em respostas imunes, torna-se necessário que essas células possuam estabilidade 
na expressão de Foxp3, que de forma complexa sofre modulações epigenéticas e pós traducionais a todo instante, o que pode afetar diretamente em suas atividades (Sawant e Vignali, 2014). Portanto, todos os processos pelo qual uma Treg é submetida, desde a sua sinalização criada por contato com citocinas e interações com complexos MHC:antígeno que acarretam em sua diferenciação, até a sua interação com um microambiente que pode interferir em sua estabilidade e função são importantes alvos de estudos para maior compreensão desse subtipo celular. Nesse contexto, se inserem também as investigações de vias metabólicas intrínsecas a essa subpopulação de linfócitos, pois essas podem afetar sua proliferação, diferenciação, função e estabilidade (Newton et al., 2016), sendo importante novos estudos sobre o tema.

\subsection{Metabolismo de Células T Reguladoras}

Linfócitos T são originados de células progenitoras presentes na medula óssea que migram para o timo, onde passam pelo processo de maturação, antes de seguirem para órgãos periféricos e participar de respostas imunes de diversas formas (Koch e Radtke, 2011). Em um primeiro momento, a célula T madura que migra do timo denominada - "Linfócito T Naïve", permanece em estado quiesciente, tendo possível ativação pelo seu TCR com o reconhecimento de um antígeno e recebimento de sinais co-estimulatórios. Após sua ativação, o linfócito T sofre um intenso processo de proliferação (expansão clonal) e adquire funções efetoras como a produção de citocinas e da expressão de moléculas específicas (Fox et al., 2005; Jones e Thompson, 2007).

As células $T$ naïve são mantidas em proliferação homeostática, o que exige pouca demanda de energia e de macromoléculas (Windt e Pearce, 2012). Dessa forma, neste estágio, os linfócitos obtêm o ATP ( Adenosina trifosfato) necessário para 
realizar suas funções básicas pela fosforilação oxidativa, utilizando principalmente glicose e ácidos graxos (Dimeloe et al., 2017). Após a apresentação de antígeno, propagam-se sinais de ativação e coestimulação dos linfócitos T CD4 (Chi, 2012), cujo processo acompanha a diferenciação celular para subpopulações efetoras Th1, Th2, Th17, de acordo com o perfil de citocinas presentes no micro ambiente (Wang et al., 2011).

No encontro com antígenos, as células T aumentam significativamente as taxas de captação de glicose, por aumento de expressão do transportador Glut1 (Transportador de glicose 1) (Frauwirth et al., 2002). Essas células priorizam a glicólise aeróbica, convertendo glicose em lactato mesmo na presença de oxigênio (Efeito Warburg), que é menos eficiente em produção de ATP, mas que pode dar o suporte energético necessário para a proliferação intensa que essas células irão sofrer posteriormente à ativação (Lunt e Vander Heiden, 2011). Nesse contexto, a sinalização coestimuladora de CD28 é crítica, uma vez que somente o receptor de células T (TCR-CD3) sozinho não consegue regular positivamente Glut 1 e a captação de glicose (Jacobs et al., 2008). Esta ligação leva à fosforilação de Akt dependente de fosfatidilinositol-3-cinase (PI3K), que pode fosforilar e aumentar a atividade da quinase alvo mamífero da rapamicina (mTOR) (Frauwirth e Thompson, 2004). mTOR é um sensor composto por dois complexos de sinalização, mTORC1 e mTORC2, os quais podem interagir com proteínas adaptadoras de diferentes formas (Linke et al., 2017). Especificamente, a ativação de mTORC1 pode modular diversos processos biológicos, incluindo o aumento da expressão de Glut-1 e de genes pró glicolíticos como HIF-1a (Hipoxia-inducible fator 1a) e c-Myc, principais fatores de transcrição envolvidos com a adaptação metabólica de células T efetoras (Chisolm e Weinmann, 2015). 
O aumento da glicólise anaeróbica em células T efetoras se encontra com aumento da demanda não só energética, mas também da demanda de metabolitos responsáveis para formação de novas biomoléculas, como nucleotídeos (via das pentoses), UDP-GlcNac (via das hexosaminas), lipídeos e aminoácidos (Lunt e Vander Heiden, 2011). Apesar de esse ser um perfil metabólico de células T efetoras, não corresponde ao metabolismo de células Tregs (Figura 1).

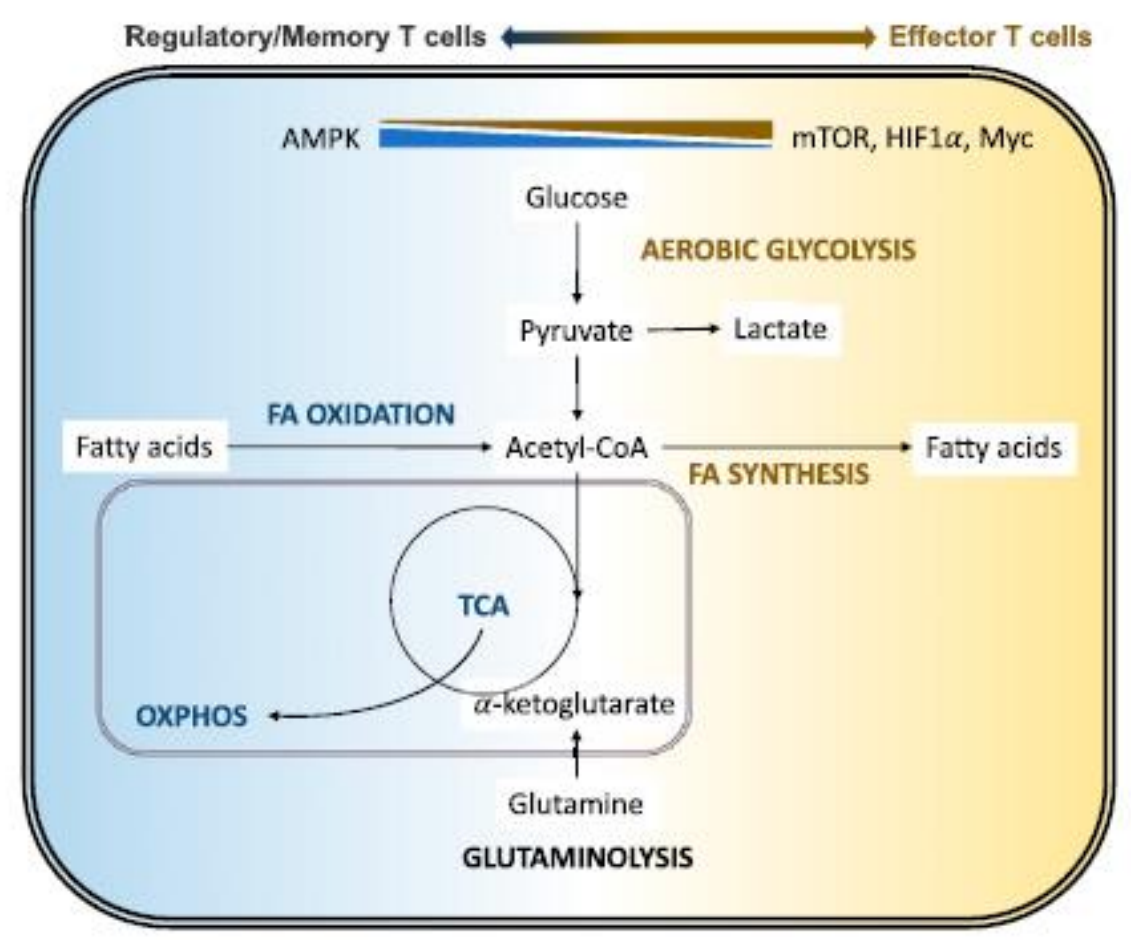

Figura 1 - Metabolismo de células T : Linfócitos T maduros nos órgãos linfoides periféricos são ativadas por APCs via ligação do TCR, co-estimulação e citocinas que funcionam como fatores de crescimento. Após isso, ocorre a reprogramação metabólica, células T efetoras, como Th1 e Th17 são altamente proliferativas e apresentam metabolismo glicolítico aeróbico acentuado. Além disso, fazem glutaminólise para sustentar o ciclo do ácido cítrico e síntese de lipídeos. As Tregs fazem glicólise convencional. A principal fonte de energia para as Tregs é a oxidação fosforilativa e de ácidos graxos (Sugiura e Rathmell, 2018).

O que se sabe em relação ao metabolismo de células Tregs é que essas células dependem, em grande parte, da fosforilação oxidativa e pela oxidação de ácidos graxos para desenvolver suas funções (Michalek et al., 2011). A via de sinalização de $\mathrm{PI3k} / \mathrm{Akt} / \mathrm{mTOR}$, importante para a via glicolítica em células T efetoras, inibe fatores de transcrição importantes para a expressão de Foxp3 (Ouyang et al., 2010). 
Inversamente a isso, o principal regulador metabólico de células Tregs, a Proteína quinase dependente de AMP (AMPK) regula negativamente as vias anabólicas, inclusive de inibir mTORC e aumentar a taxa de oxidação de ácidos graxos e, consequentemente, gerar maior produção de ATP (Oakhill et al., 2012; O'neill e Hardie, 2013; Almeida et al., 2016; Galgani et al., 2016). Além disso, a expressão de Foxp3 promove redução da ativação de Akt e mTOR, assim como a expressão de HIF-1a e Glut1 (Gerriets et al., 2016). Simultaneamente, Foxp3 também é capaz de gerar aumento de PTEN (Phosphatase and tensin homolog).

Foxp3 também é capaz de gerar aumento de PTEN e este, por sua vez, reduz a ativação de PI3k/Akt, que contribui para a manutenção da expressão de Foxp3 nas Tregs, garantindo uma maior estabilidade e função dessas células (Buckler et al., 2006). Também já foi demonstrado que a alta expressão de Foxp3 aumenta a expressão de genes envolvidos na captação de ácidos graxos e de peptídeos, além de inibir moléculas envolvidas na glicólise, metabolismo de glutamina, síntese de colesterol e de nucleotídeos (Gerriets et al., 2016). O Foxp3 também já demonstrou ser suficiente para gerar aumento da capacidade respiratória por regular positivamente todos os componentes do complexo de transporte de elétrons, gerando aumento da produção de ATP pela fosforilação oxidativa (Howie et al., 2017).

Apesar da glicólise ser classicamente descrita como prejudicial à estabilidade e função de Tregs, a inibição da enzima hexocinase (HK), porta de entrada para a via glicolítica, já foi vista gerando diminuição da expressão de importantes variantes do Foxp3 (De La Rosa et al., 2004). Nesse mesmo sentido, em ambientes ricos em lactato e com escassez de glicose foi relatado que Foxp3 pode reprogramar o metabolismo de Tregs, suprimindo a glicólise e glutaminólise e promovendo um maior uso da fosforilação oxidativa, acompanhado de uma elevação dos níveis de 
NAD:NADH (Angelin et al., 2017). As células Tregs também conseguem proliferar em condições inflamatórias, um processo suportado pela glicólise (Gerriets et al., 2016). Além disso, dados do nosso grupo de pesquisa também demonstraram que a glicólise é essencial para a geração de iTregs, pois a ausência da glicose na cultura comprometeu substancialmente a diferenciação dessas células (Melo et al., 2019 em preparo). Dessa maneira, esses dados demonstram como as tregs são capazes de realizar suas funções funcionar em ambientes desfavoráveis e de como elas se adaptam em diferentes respostas reprogramando o metabolismo celular. Necessitando assim de mais estudos para a maior compreensão do metabolismo dessas células que pode estar utilizando de metabolitos da glicose em vias alternativas, como a das hexosaminas.

\subsection{Via dAS heXosaminas E O-GLCNACILAÇÃo}

A glicose além de suprir demandas energéticas também é capaz de participar da síntese de novas biomoléculas importantes para o funcionamento do metabolismo das mais diversas células (Sun et al., 2016). Nesse contexto, insere-se a via das hexoaminas, que tem como produto a formação de UDP-GlcNAc (Uridina difosfato Nacetil-D-glucosamina), formado pela da junção do catabolismo de glicose, lipídeos, nucleotídeos e aminoácidos, o qual é adicionado de resíduos de serina/treonina, alterando a função e/ou estabilidade de diferentes proteínas, constituindo uma alteração pós-traducional chamada de O-GlcNAcilação (Harwood e Hanover, 2014).

A glicose presente no citoplasma após passar por transportadores GLUT é imediatamente fosforilada por hexoquinases, culminando na formação de glicose-6- 
fosfato (Wilson, 2003), que pode ser utilizada para dar continuidade à via glicolítica para suprir demandas energéticas, armazenada como glicogênio, seguir para via das pentoses fosfato e posteriormente sofrer oxidação e gerar NADPH ou ser isomerizada pela fosfoglicoisomerase à frutose-6-fosfato (F6P) (Hurtado-Guerrero et al., 2007). Esse metabólito intermediário da glicólise pode ser desviado (2\% a $5 \%$ ) do seu destino de ser fosforilado novamente para seguir definitivamente na rota glicolítica e servir para substrato da enzima Frutose-6P-amidotransferase (GFAT), ponto inicial da via das hexoaminas (Buse, 2006).

A GFAT catalisa a hidrólise de glutamina em glutamato e amônia, além da aminação juntamente com a isomerização da F6P gerando a D-glucosamina-6P (DG6P) neste processo, que é utilizada como substrato da enzima GNPNAT1 (glucosamina-6P Nacetiltransferase) que por sua vez é capaz de desacetilar acetilCoA e em seguida acetilar D-G6P, levando a formação de N-acetil-D-glucosamina-6P (Vyas et al., 2013). Após isso, este composto é convertido em Nacetil-D-glucosamina1P pela fosfoglicomutase 3 (PGM3), que pode receber um nucleotídeo que ativa sua estrutura através de outra enzima denominada UDP-N-acetilglicosamina pirofosforilase1 (UAP1) culminando na produção de UDP-N-Acetil-D-glucosamina (UDP-GlcNac) (Figura 2) (Buse, 2006; Hurtado-Guerrero et al., 2007; HurtadoGuerrero et al., 2008). 


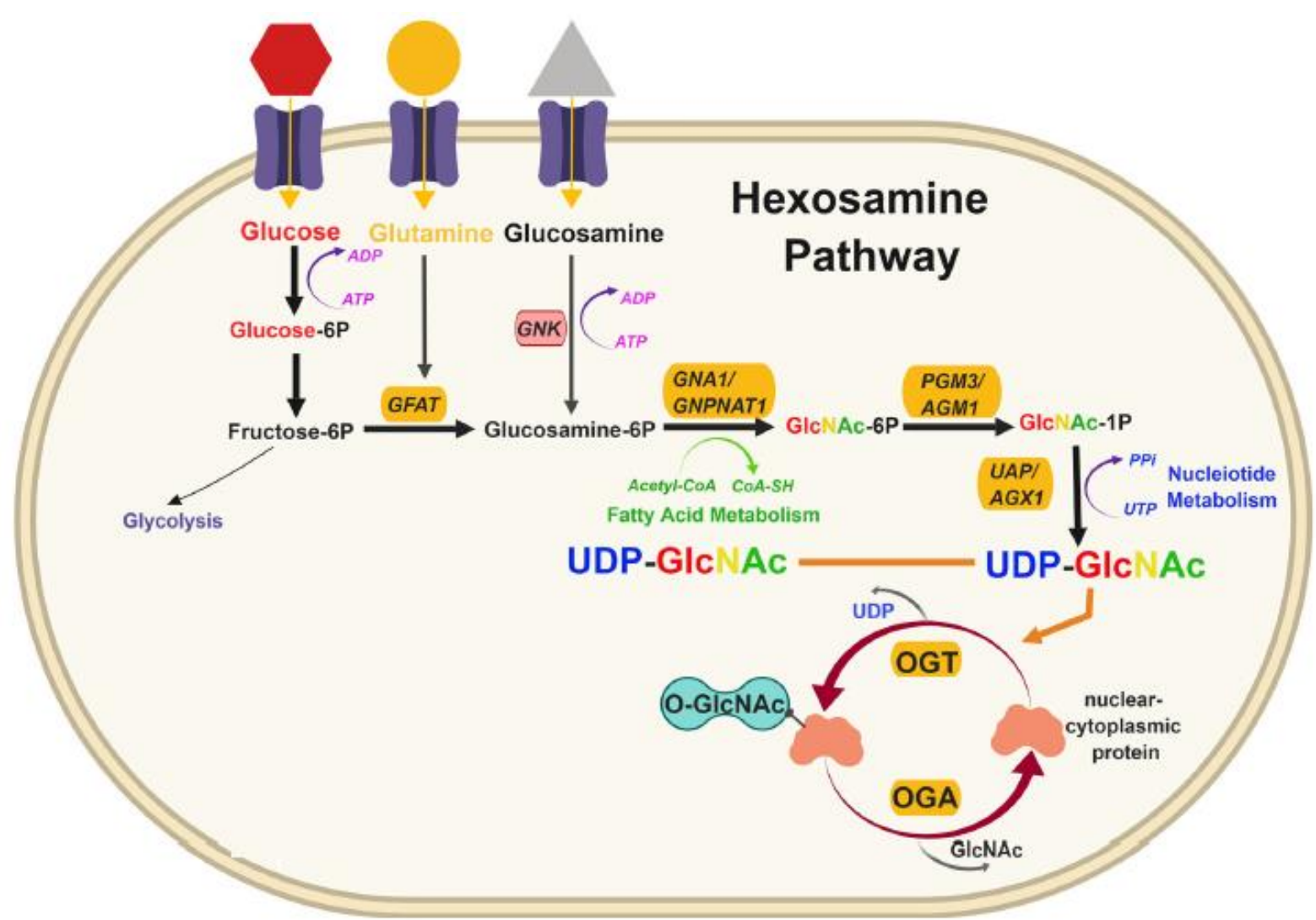

Figura 2 - Via das Hexoaminas: Etapas do processo para a formação e adição de GlcNAc em proteínas (Akella et al., 2019)

UDP-GlcNAc possui uma função estrutural, sendo responsável pela síntese de glicoproteínas, glicolipídeos, proteoglicanas e glicosaminas (Schleicher e Weigert, 2000). Além disso, também possui função modulatória através de mudanças póstraducionais onde moléculas de GlcNAc são inseridas em hidroxilas de resíduos de serina e/ou treonina de proteínas alvos localizadas no núcleo, citoplasma ou em mitocôndrias das células, processo denominado O-GlcNAcilação (Sun et al., 2016). Tal fenômeno é catalisado por um par de enzimas: a OGT (O-glicosiltransferase), que insere as moléculas de GlcNac; e a OGA (OGlcNacase), que possui papel de remover GlcNAc (Bond e Hanover, 2015). Juntas essas enzimas regulam os níveis de OGlcNAc, sendo de suma importância para o crescimento e sobrevivência celular, através de sustentação de vias de sinalização, captação de nutrientes, degradação 
de proteínas mal dobradas, redução de apoptose celular e homeostase do retículo endoplasmático (Gélinas et al., 2018).

A O-GlcNAcilação é considerada essencial para a sobrevivência de células T, e a exclusão condicional de OGT em células T demonstrou induzir apoptose dessas células tanto no timo quanto na periferia (O'donnell et al., 2004). Já se tem demonstrado também que o bloqueio da O-GlcNacilação inibe o processo de expansão clonal e que a ativação do TCR de células T é capaz de aumentar os níveis de proteínas O-GlcNAciladas (Lund et al., 2016; Swamy et al., 2016). Níveis elevados de O-GlcNAc se correlacionam com o aumento da secreção pró-inflamatória da citocina IL-17A por células T CD4 + murinas e também são funcionalmente importantes nas células Tregs, modificando FOXP3 (Liu, Bing et al., 2019; Machacek et al., 2019). Corroborando com essas informações, dados do nosso laboratório demonstraram que este evento pode controlar a diferenciação de Tregs uma vez que a inibição da GFAT (etapa limitante do ciclo das hexoaminas; Azaserina, iGFAT), bem como a ausência de OGT (enzima que transfere o O-GlcNAc) nas células T CD4 (OGTfl/flCD4cre+) ou sua inibição (BADGP, iOGT), diminuindo a expressão de Foxp3 (Melo et al., 2019 em preparo). Esses resultados mostram a importância do estudo de vias metabólicas negligenciadas importantes para a diferenciação e estabilidade de Treg, além das vias clássicas, proporcionando um maior conhecimento sobre o metabolismo dessas células.

\subsection{ENZIMA 6-FOSFOFRUTO-2-QUINASE/FRUTOSE-2,6-BIFOSFATASE-3}

A taxa do fluxo glicolítico é controlado em diferentes níveis: disponibilidade dos substratos participantes das 10 etapas existentes no processo; de efeitos alostéricos; 
enzimas e outros componentes reguladores (Chesney, 2006). Após a glicose entrar nessa via, primeiramente a enzima denominada hexocinase (HK) fosforila a glicose para formar a G6F que pode ser convertida em glicogênio, ser oxidada pela via das pentoses fosfato gerando produção de NADPH ou, como é observado na maioria das vezes, a isomerização desse composto em frutose-6-fosfato (F6P) (Wilson, 2003). A reação irreversível feita pela HK e a isomerização posterior a ela ainda não garante o comprometimento das moléculas derivadas da glicose com a via glicolítica, portanto, deve ocorrer a conversão de F6P em frutose 1,6-bifosfato (F1,6BP) por uma enzima denominada 6-fosfofrutoquinase-1 (PFK-1), que é conhecida por ser a responsável pela etapa de comprometimento definitivo e irreversível com a via glicolítica (Weber, 1977).

A PFK-1 determina o ritmo da glicólise, mas também é modulada por vários efeitos alostéricos, sendo o ATP o mais potente inibidor da enzima, causando um feedback negativo (Efeito Pasteur) (Van Schaftingen et al., 1981). Além disso, o fluxo também pode ser suprimido pelo hormônio glucagon, que diminui a afinidade da PFK1 com o seu substrato, a F6P (Van Schaftingen et al., 1980). De modo contrário, um composto denominado frutose-2,6-bifosfato $(\mathrm{F} 2,6 \mathrm{BP})$ ativa alostericamente a PFK-1, mudando seu equilíbrio conformacional de baixa afinidade por F6P para um estado de alta afinidade, mesmo na presença de ATP (Chesney, 2006).

A concentração de F2,6BP depende uma família de enzimas bifuncionais, as 6-fosfofruto-2-quinase/frutose-2,6-bifosfatases (PFK-2 / FBPases), capazes de fosforilar F6P a F2,6BP ou mesmo desfosforilar F2,6BP a F6P. Essas enzimas são codificadas por quatro genes (PFKFB1-4) e são encontradas em diversos tecidos (Sakakibara et al., 1997). Especificamente uma delas, codificada pelo gene PFKFB3, 
é conhecida por ser induzida por estímulos, como hipóxia através de HIF-1a (Bartrons e Caro, 2007), mitogênicos (Houddane et al., 2017), inflamatórios como IL-6 (Bartrons, Simon-Molas, et al., 2018) e LPS (Ruiz-García et al., 2011), além de hormônios e eventos celulares estressantes (Bartrons, Rodríguez-García, et al., 2018). Embora seja necessário a co-expressão de várias PFK-2 / FBPases para regular a síntese de F2B,6BP, em fibroblastos de camundongos $\mathrm{PFKFB3}^{+/-}$foi encontrada uma diminuição substancial na concentração intracelular de F2,6BP (Telang et al., 2006). Além disso, as diferenças reveladas por cristalografia em suas alças para os substratos ATP e F6P parecem garantir uma maior ligação do substrato nessa isoenzima, se comparada com as outras. Adicionalmente, enquanto nas enzimas codificadas pelos genes PFKFB1 e PFKFB4 ocorre uma obstrução de domínios C-terminais responsáveis pela atividade quinase, inibindo assim a mesma, o mesmo não é visto na que é codificada pelo gene PFKFB3, sendo assim mais flexível e mais ativa (Kim et al., 2006; Michels e Rigden, 2006).

A atividade quinase relativamente elevada da enzima codificada pelo gene PFKFB3 é de grande importância para estabelecer a concentração de F2,6BP no citosol e aumentar consideravelmente o fluxo de moléculas na glicólise e a ativação das diferentes quinases em microambientes hipóxicos, isquêmicos ou estressantes pode ser crítica para a sobrevivência celular e, portanto, representar um mecanismo protetor para células metabolicamente deprimidas ou deficientes em ATP. Nesse contexto, o produto do gene PFKFB3 é também regulado por modificações covalentes, podendo o domínio C-terminal ser fosforilado em Ser461 por diferentes proteínas cinases, dentre elas, a AMPK (Marsin, A.-S. et al., 2002; Okamura e 
Sakakibara, 2014) e a via PI3K / Akt (Marsin, A.-S. et al., 2002; Simon-Molas, Helga et al., 2018), que possuem importante papel para o metabolismos células T.

No entanto, poucos trabalhos avaliaram o papel de PFKFB3 em células T. Atualmente sabe-se que o processo de ativação de linfócitos T exige uma grande quantidade de energia para que ocorra proliferação e diferenciação celular, e que este mecanismo está associado ao aumento da expressão de PFKFB3 e seu substrato, o F2B,6BP (Telang, S. et al., 2012; Simon-Molas, H. et al., 2018). A PFKB3 também já foi descrita no contexto de transplantes, no qual sua inibição farmacológica levou a redução da resposta enxerto versus hospedeiro (Nguyen et al., 2016). De modo interessante, a inibição de PFKFB3 também foi capaz atenuar a ativação de células T in vitro, que refletiu em uma menor resposta dependente de células $\mathrm{T}$ no modelo de psoríase (Telang, S. et al., 2012), entretanto o mecanismo pelo qual isso ocorre permanece pouco compreendido.

Apesar de não se ter nada descrito sobre o envolvimento dessa enzima no metabolismo de células Tregs, os resultados preliminares do presente trabalho demonstraram que a inibição da enzima PFKFB3 promove uma maior diferenciação de Tregs, sendo importante a investigação de como a PFKBFB3 atua nos eventos metabólicos decorrentes da ativação e diferenciação de células T reguladoras. 


\section{HIPÓTESE}

A hipótese do presente estudo é que a inibição da PFKFB3 modula positivamente a diferenciação e função de células Tregs, uma vez que a redução da função dessa enzima leva ao acúmulo de moléculas como a frutose-6-fosfato que podem seguir para a via das hexosaminas (Figura 3). Sendo um possível alvo para tratamentos de doenças autoimunes.

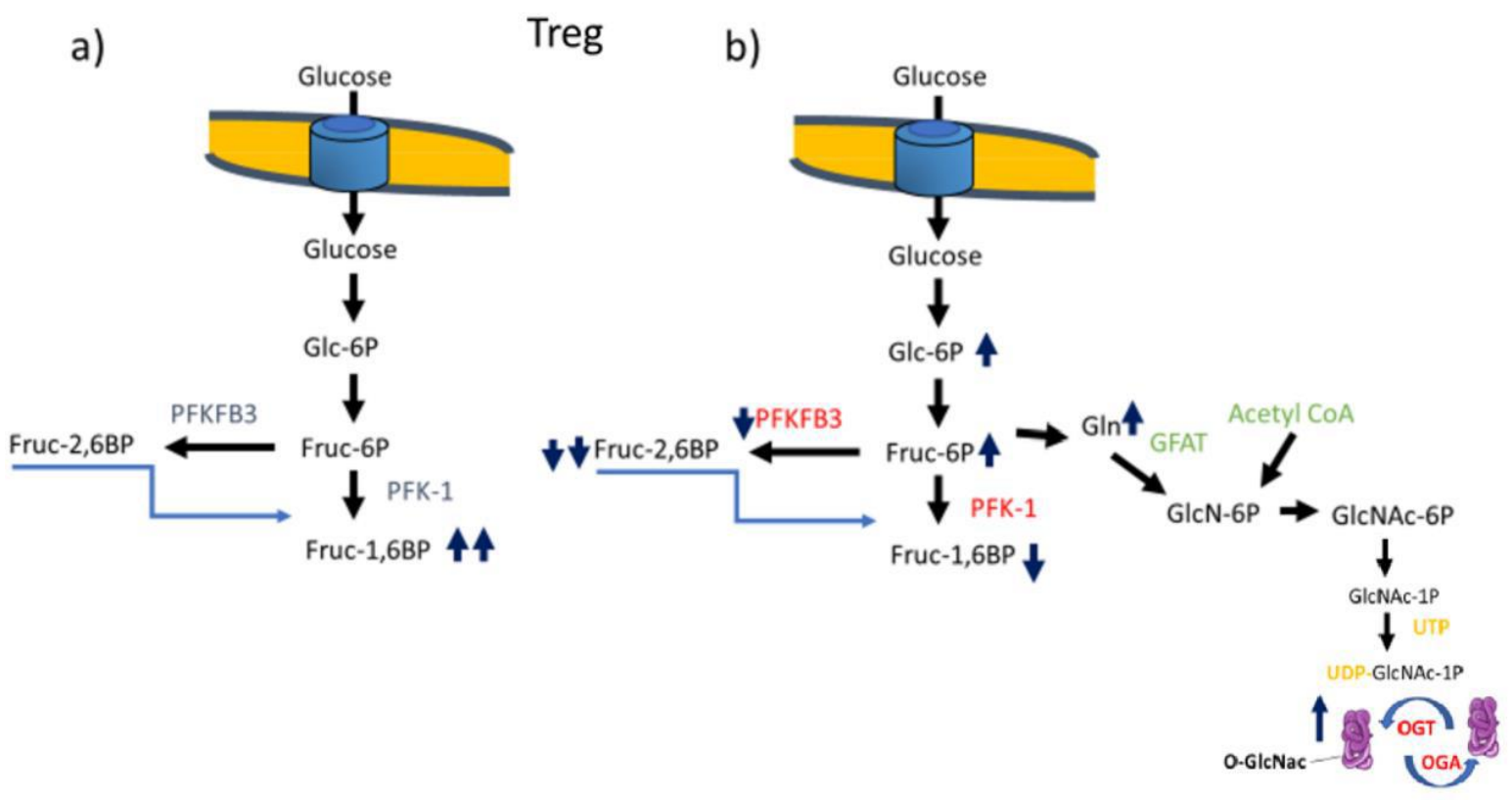

Figura 3 - a) PFKFB3 e sua função na via glicolítica; b) Possíveis efeitos da inibição da enzima em células T reguladoras. Fonte: elaborado pelo próprio autor 


\section{OBjetivos}

\subsection{OBJetivo GERAL}

Determinar o papel da enzima PFKFB3 em células T reguladoras.

\subsection{OBJetivos ESPECíficos}

- Avaliar a expressão da enzima PFKFB3 em células T reguladoras.

- Avaliar se ocorre o acúmulo de metabólitos na via das hexosaminas como consequência da inibição da enzima PFKFB3.

- Verificar o efeito da inibição da enzima PFKFB3 na diferenciação de células T reguladoras

- Verificar a expressão da enzima PFKFB3 durante o modelo de encefalomielite autoimune experimental (EAE)

- Verificar o efeito da inibição da enzima PFKFB3 no modelo de encefalomielite autoimune experimental (EAE) 


\section{MATERIAIS E MÉtOdOS}

\subsection{ANIMAIS DE EXPERIMENTAÇÃo}

Foram utilizados camundongos da linhagem C57BL/6, provenientes do biotério central da Universidade de São Paulo (USP) - Campus de Ribeirão Preto.

\subsection{INDUÇÃO DA ENCEFALOMIELITE AUTOIMUNE EXPERIMENTAL}

EAE foi induzido por imunização subcutânea com emulsão contendo $200 \mu \mathrm{g}$ do antígeno peptídeo MOG35-55 (glicoproteína da mielina de oligodendrócitos) em CFA (adjuvante completo de Freund) suplementado com $5 \mathrm{mg} / \mathrm{mL}$ de Mycobacterium tuberculosis em ambos os lados dos flancos traseiros. Foi injetado toxina pertussis (PTx) em uma dose de 200ng por animal (i.p), no dia da imunização e 48h depois. 0 escore clínico dos animais foi monitorado diariamente utilizando-se escalas padronizadas: 0. Nenhum sinal clínico; 1. Cauda flácida; 2. Marcha cambaleante, déficit de equilíbrio 3. Paralisia parcial dos membros posteriores; 4. Paralisia completa dos membros posteriores; 5. Paralisia completa dos membros posteriores com fraqueza de membros anteriores ou moribundo. 


\subsection{Ferramentas farmacológicas}

Para investigar o papel da PFKFB3 foi utilizado as ferramentas farmacológicas Calbiochem, inibidor de PFKFB3 (3PO) e o YZ9 nos experimentos in vitro na concentração de $0,3 \mu \mathrm{M} 1,0 \mu \mathrm{M}$ e 3,0 $\mu \mathrm{M}$. Nos experimentos in vivo utilizamos do 3PO $25 \mu \mathrm{g} / \mathrm{Kg}$, sendo o tratamento diário e iniciado no dia 6 após a imunização e encerrado no dia 14 após a imunização. Também foi utilizado do inibidor de OGT, BADGP na concentração de 10,0 $\mu \mathrm{M}$ em experimentos in vitro.

\subsection{Cultura de células Tregs}

O baço e linfonodos dos animais foram removidos e as células T CD4+ obtidas por meio de kit de isolamento (CD4+ T Cell Isolation Kit e Anti-PE - Miltenyi Biotec). Posteriormente, as células foram cultivadas em RPMI-C, com estímulos de proliferação (anti-CD3 e antiCD28 BD Biosciences; $1 \mu \mathrm{g} / \mathrm{ml}$ ) durante 96 horas $\left(37^{\circ} \mathrm{C}\right.$, $5 \%$ CO2), em condições polarizantes para a diferenciação de células Tregs $(1,0 \mathrm{ng} / \mathrm{ml}$ de TGF- $\beta$ ). Além disso, linfócitos T CD4+ isolados de animais foram cultivados também na presença de 3PO (e/ou Yz9) ambos inibidores de PFKFB3 e também na presença do inibidor de OGT (BADGP). Em seguida, marcação intracelular para Foxp3 e outras moléculas extracelulares será realizada e os resultados serão adquiridos por citometria de fluxo (Facs Verse BD Biosciences). 


\subsection{Marcação Celular e Citometria}

Linfócitos $T$ dos baços e linfonodos drenantes de animais imunizados ou células $\mathrm{T}$ diferenciadas in vitro foram coletadas, Em seguida, as células foram marcadas com anticorpo anti-CD4, fixados e permeabilizadas (Cytoperm/Cytofix e Perm/wash - BD Biosciences) para posterior marcação intracelular de Foxp3, os dados foram adquiridos por Facs Verse BD Biosciences, e analisados pelo software FlowJo.

\subsection{Avaliação da Lesão Tecidual}

Os animais foram eutanasiados e perfundidos por via intracardíaca com PBS seguido de PFA 4\%. A medula espinhal foi removida, dissecada e incubada overnight em PFA 4\%. O tecido do sistema nervoso central (SNC) foi embebido em parafina, emblocado e então seccionado (5-7 $\mu \mathrm{m})$. Posteriormente, os cortes foram preparados em lâminas e corados com hematoxilina e eosina (H\&E; Sigma-Aldrich) para análise de infiltrado de células inflamatórias e desmielinização, respectivamente, de acordo com as especificações do fabricante.

\subsection{EXTRAÇÃO DE MRNA E CONVERSÃo DE CDNA}

A extração de RNA total da cultura de linfócitos de células T CD4+ isoladas do linfonodo foi realizada utilizando kit de extração RNeasy Mini Kit 250 (Qiagen) de 
acordo com as instruções de fabricante. Para extração de RNA total de tecido do SNC, as medulas espinais foram coletadas em tubos contendo $500 \mu \mathrm{L}$ de TRIzol® reagente (Invitrogen $^{\mathrm{TM}}$ ) e processadas com homogenizador (IKA T 10). Em cada tubo foram adicionados $200 \mu \mathrm{L}$ de clorofórmio (Merck) e $100 \mu \mathrm{L}$ de agua ultrapura (SigmaAldrich). As amostras foram agitadas no vortex e centrifugadas a 14000 rpm por 15 minutos a $4^{\circ} \mathrm{C}$. A fase aquosa (RNA) foi coletada e transferida para outro tubo contendo $500 \mu \mathrm{L}$ de isopropanol (Merck) gelado. As amostras foram agitadas (vortex) e incubadas overnight a $-20^{\circ} \mathrm{C}$. Em seguida, as amostras foram novamente centrifugadas nas mesmas condições anteriores e o sobrenadante descartado cuidadosamente. O resíduo de RNA foi lavado com $500 \mu \mathrm{L}$ de álcool etílico $80 \%$ e $500 \mu \mathrm{L}$ álcool etílico absoluto, sucessivamente. Em cada lavagem as amostras foram vortexadas e centrifugadas a $7000 \mathrm{rpm}$ por $10 \mathrm{~min}$ a $4^{\circ} \mathrm{C}$. O sobrenadante foi descartado e o pellet de RNA foi ressuspendido em agua ultrapura (Sigma-Aldrich). Em ambos protocolos, a concentração de RNA foi determinada por meio da densidade ótica $(260 \mathrm{~nm})$ utilizando o aparelho NanoDrop ${ }^{\mathrm{TM}}$ (ThermoFisher Scientific). A conversão de mRNA a cDNA foi realizada utilizando o kit de transcrição reversa High Capacity (Applied Biosystems ${ }^{\mathrm{TM}}$ ). A quantidade de $500 \mathrm{ng}$ de RNA total extraídos a partir de lisado de células T CD4+ ou de tecido do SNC foi utilizada para cada reação, as quais foram conduzidas de acordo com as recomendações do fornecedor.

\subsection{REAÇÃo EM CADEIA dA POLIMERASE QUANTITATIVA EM TEMPO REAL (RT- QPCR)}

A PCR quantitativa em tempo real foi realizada por meio do aparelho stepOne Plus Real-Time PCR System, usando o sistema de fluorescência SYBR-green® Master Mix (Applied Biosystems ${ }^{\mathrm{TM}}$ ). Cada PCR em tempo real foi feita com volume 
final de $10 \mu \mathrm{L}$, contendo: $5 \mu \mathrm{L}$ de SYBR-green ${ }^{\circledR}+0,25 \mu \mathrm{L}$ de primer forward (ou sense) $+0,25 \mu \mathrm{L}$ primer reverse (ou anti-sense) $+3,5 \mu \mathrm{L}$ de agua ultra-pura $+1 \mu \mathrm{L}$ da amostra de cDNA. As placas contendo as amostras e os reagentes mencionados foram submetidas ao seguinte protocolo de ciclagem: 1 ciclo de $95^{\circ} \mathrm{C}(10 \mathrm{~min})+40$ ciclos de $95^{\circ} \mathrm{C}$ (15 seg) e $60^{\circ} \mathrm{C}$ (1 min). A curva de dissociação (curva de melting) foi obtida em três etapas, 15 segundos a $95^{\circ} \mathrm{C}, 1$ minuto a $60^{\circ} \mathrm{C}$ e mais 15 segundos a $95^{\circ} \mathrm{C}$, para verificar se apenas um produto foi amplificado. Amostras que tiveram mais de um pico foram excluídas. Os resultados foram analisados através do método comparativo de "cycle threshold" (CT) (2^ $\Delta \Delta \mathrm{CT})$. Os níveis de expressão relativa dos genes alvos foram normalizados com base na expressão de Gapdh como controle endógeno. A expressão genica foi baseada na quantidade de vezes que aumentou em relação as células fresh ou ao grupo naïve (calibradores). Nenhum dos primers utilizados produziu amplificação no branco, ou apresentou mais de um pico na curva de melting. Além disso, todos apresentaram eficiência maior que $90 \%$.

\subsection{WESTERN BLOT}

Células T CD4+ foram coletadas e resuspendidas em solução RIPA Buffer ${ }^{\circledR}$ com Cocktail de inibidor de protease e fosfatase (Thermo scientific). Para coleta da medula espinal, os animais foram perfundidos com PBS 1x e o tecido armazenado em RIPA Buffer ${ }^{\circledR}$ com inibidor de protease e fosfatase e posteriormente processados com homogenizador (PolytronR). Alíquotas das amostras foram coletadas para dosagem de proteínas pelo método de BCA (Bicinchoninic Acid Protein Assay; Sigma Aldrich). Amostras contendo $20 \mu \mathrm{g}$ de proteína foram incubados com tampão de amostras (2x 
Laemmli Sample Buffer; Bio-Rad) na proporção de 1:1, a 95ํㄷ durante 10 min, para desnaturação. Posteriormente, as amostras foram aplicadas em gel de poliacrilamida de $10 \%$ na presença de SDS (SDS-PAGE) para separação por eletroforese (MiniProtean II Eletrophoresis Cell, Bio-Rad). As proteínas separadas foram transferidas para membrana de nitrocelulose $0.2 \mu \mathrm{m}$ (Amersham Pharmacia Biotech), utilizando o sistema de transferência Trans Blot Turbo (Bio-Rad). Após transferência, as membranas foram lavadas em agua deionizada e o bloqueio dos sítios antigênicos inespecíficos foi realizado pela incubação das membranas com TBST (Tris-HCl 100 $\mathrm{mM} \mathrm{pH} \mathrm{7,5,} \mathrm{NaCl} 150 \mathrm{mM}$, Tween20 0,05\%) com 5\% de leite pó por $1 \mathrm{~h}$. Em seguida, as membranas foram lavadas com TBST e incubadas com anticorpos primários PFKFB3 ou RL2 (1:1000; Cell Signalling) overnight a 4ㄷ, sob leve agitação. Anticorpos secundários anti-rabbit ou anti-mouse (1:5000; Cell Signaling) conjugados a HRP foram adicionados e incubados por $1 \mathrm{~h}$ a temperatura ambiente sob lenta agitação. Logo, as membranas foram novamente lavadas com TBST por 30 minutos. Para revelar as membranas, foi utilizado substrato Luminata (Millipore) para a detecção por quimiluminescência utilizando o equipamento ChemiDocTM XRS com o software ImageLab 3.0 (Bio-Rad). $\beta$-actina foi utilizada como controle endógeno.

\subsection{IMUNOFLUORESCÊNCIA}

Os animais foram anestesiados com $2 \%$ de isoflurano, e perfundidos com PBS 1x, seguido de paraformaldeido 4\% (PFA; $\mathrm{pH} 7,3-7,4)$. As medulas espinais foram coletadas e fixadas em paraformaldeido (PFA) a 4\%. O material foi acondicionado em uma solução de sacarose 30\% em PBS 1x por no mínimo 72h. Em seguida, os tecidos foram alocados em meio para congelamento Tissue-TekR O.C.T. ${ }^{\text {TM }}$ (Sakura Finetek), 
congeladas em gelo seco e estocadas a $-70^{\circ} \mathrm{C}$. Os cortes (secções) foram confeccionados em criostato (Leica CM1850, Alemanha) com espessura de $20 \mu \mathrm{m}$ e então estocados PBS 1x (2 mL). As laminas foram incubadas em metanol P.A (10 min; $20 \stackrel{\circ}{\circ}$ ), lavadas 3 vezes por 5 min em PBS $1 x$ e incubadas em uma solução de PBS suplementada com glicina $(0,1 \mathrm{M} ; 30 \mathrm{~min})$. Outra incubação foi realizada utilizando PBS contendo $2 \%$ de BSA e $0,2 \%$ de Triton X100. Posteriormente, o dye fluorescente para marcação de mielina FluoroMyelin (ThermoFisher Scientific) foi incubado de acordo com as instruções do fabricante. Para imunofluorescencia de células, os linfócitos T obtidos a partir das culturas foram coletados, fixados, permeabilizados em laminas. Posteriormente, os preparados, fixados e permeabilizados com anticorpos primários anti-PFKFB3 e FOXP3 (1:200; Biolegend), seguidos da adição de anticorpos secundários conjugados a fluoroforo. Por fim, as lamínulas foram introduzidas nas laminas juntamente com o meio de montagem Prolong® gold antifade reagent com DAPI (marcação nuclear). As imagens foram captadas por microscópio confocal Leica TCS SP5 e analisadas no software Image J.

\subsection{ANÁLISE ESTATíSTICA}

Foi utilizado analise de variância ANOVA de uma via (one way), seguido do teste (post-hoc) de Tukey para comparação entre os diferentes grupos. ANOVA de duas vias (two way), seguindo do teste de Bonferroni, foi utilizada para avaliação do curso temporal do escore clinico da EAE entre os grupos. Para se comparar dois grupos de variáveis não-pareadas, utilizou-se o teste t de student. Os dados foram expressos como media \pm E.P.M., sendo representativos de 2-3 experimentos independentes. Experimento in vivo foi realizado com $n=4$ animais por grupo. 
Diferenças estatísticas foram consideradas quando $P<0,05$. As analises estatísticas e confecção gráfica foram realizadas através do programa estatístico GraphPad Prism 7.0.

\section{Resultados}

\subsection{A enZima PFKFB3 é eXPRESSA dURANTE A difERENCIAÇÃo de CÉlULAS T REGULADORAS IN VITRO}

As Células Tregs Foxp3+ utilizam principalmente da fosforilação oxidativa e da oxidação de ácidos graxos para desenvolver suas funções (Michalek et al., 2011). No entanto, atualmente, o processo de glicólise também vem demonstrando ter sua importância no metabolismo dessas células (Gerriets et al., 2016; Angelin et al., 2017; Grzes et al., 2017). Neste contexto, sabe se que ajustes críticos no fluxo glicolítico são definidos por diversos fatores que modulam esta via, um dos mais importantes seria a biomolécula F2,6BP, que ativa o PFK1 e, por si só, é sintetizado e degradado por uma família de enzimas bifuncionais, as 6-fosfofructo-2-quinase / frutose-2,6 bisfosfatases, (PFKFBs) em especial a enzima codificada pelo gene PFKFB3 por possuir uma atividade quinase mais elevada (Moncada et al., 2012).

No contexto de células Tregs ainda não existem trabalhos que explorem a enzima PFKFB3, sendo este o primeiro. Portanto, para investigarmos o papel dessa enzima nessa subpopulação de linfócitos, primeiramente precisávamos avaliar como é sua expressão durante a diferenciação de células Treg. Para isso ativamos células T CD4+ CD25- com anti-CD3/CD28 na presença de TGF- $\beta$ ou não e avaliamos a expressão de gênica de PFKFB3 e FOXP3 em três períodos diferente (3 horas, 6 
a)

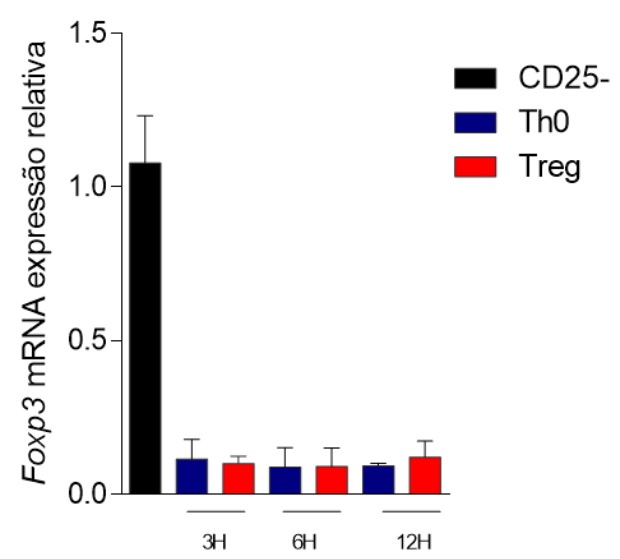

b)

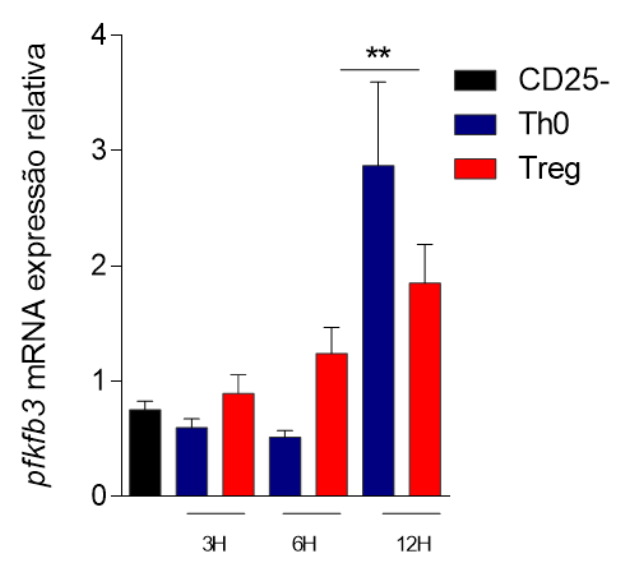

Figura 4 - Expressão gênica de PFKFB3 nos estágios iniciais de diferenciação de células T reguladoras: Linfócitos T CD4+CD25- provenientes de animais C57BL/6 foram isolados e cultivados sob condições polarizantes para Treg. As células foram coletadas em diferentes momentos (3, 6, 12h), sendo extraído o RNA e realizado o qPCR para: a) Foxp3 e b) PFKFB3. Os resultados foram obtidos por ANOVA de uma via, seguida pelo teste de Tukey. Foi utilizado o grupo fresh como calibrador para a análise, sendo os resultados analisados através do método 2- $\Delta \Delta C T$, com correção da expressão genica realizada pela expressão de Gapdh. Os resultados foram obtidos por ANOVA de duas vias, seguida pelo teste de Bonferroni. Dados estão expressos em Média \pm E.P.M. ${ }^{* *} P<0,01$.

horas e 12 horas) (Figura 4). Utilizamos células $\mathrm{T}$ ativadas somente por antiCD3/CD28 (Th0) como controle nesses diferentes tempos, visto que o estímulo de TGF- $\beta$ não tem efeito na expressão de Foxp3, ou seja, não existe diferenciação de Tregs ainda (Figura 4a).

A cinética escolhida para esse experimento se deve ao fato de que a enzima PFKFB3 não é expressa sem a presença de um estímulo e é sabido que sua expressão é nos estágios iniciais da ativação de células T por estímulo do TCR (antiCD3/CD28) (Telang, S. et al., 2012; Simon-Molas, H. et al., 2018). Porém, nada se tem quanto a influência do TGF- $\beta$ na expressão de PFKFB3 em linfócitos T e de acordo com nossos resultados, TGF- $\beta$ parece restringir a expressão gênica dessa enzima (Figura 4b).

Em seguida verificamos o perfil de expressão em nível proteico (Figura 5), sendo assim, células foram coletadas para Western Blot em diferentes tempos (24 horas; 48 horas; 72 horas) da cultura de linfócitos que sofreram só estímulo de anti- 
CD3/CD28 (Th0) e as que também estavam na presença de TGF- $\beta$ (Treg) (Figura

5a). Corroborando com o dado da Figura 4, foi observado uma diminuição da expressão de PFKFB3 no grupo que estava na presença de TGF- $\beta$, no entanto foi visto que o pico de expressão proteica da enzima PFKFB3 é no período de 24 horas após o início da cultura de linfócitos T reguladores e que sua expressão diminui no decorrer do tempo de $48 \mathrm{~h}$ e se tornando menor ainda em $72 \mathrm{~h}$. Além disso, também coletamos células para imunoflorescência no tempo de 48 horas ( Figura 5b) e verificamos a expressão de FOXP3 e PFKFB3 simultaneamente nessas células, demonstrando assim que a enzima está presente em linfócitos FOXP3+ após 48h.

a)

) $\begin{array}{lllllll}\text { CD25- } & \text { Th0 } & \text { Th0 } & \text { Tho } & \text { Treg } & \text { Treg } & \text { Treg } \\ & 24 \mathrm{~h} & 48 \mathrm{~h} & 72 \mathrm{~h} & 24 \mathrm{~h} & 48 \mathrm{~h} & 72 \mathrm{~h}\end{array}$

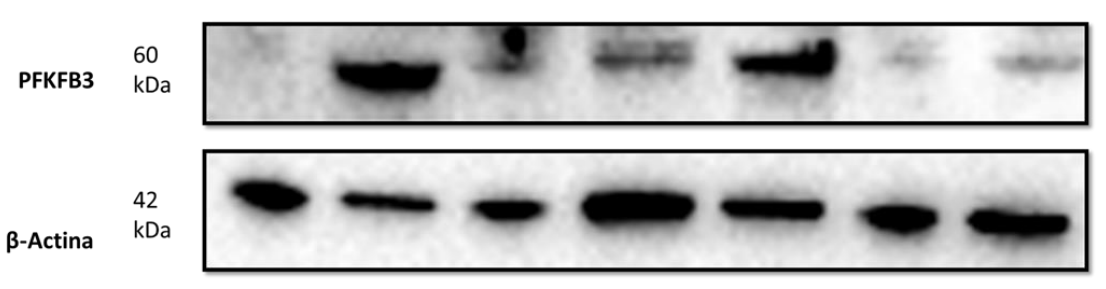

b)

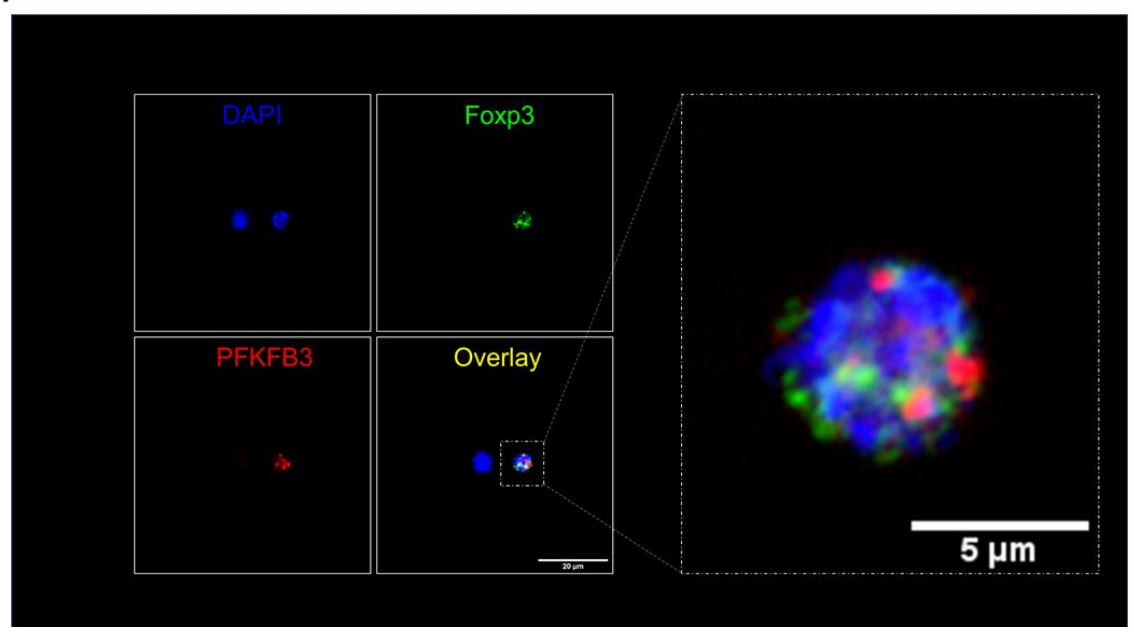

Figura 5 - Expressão proteica de PFKFB3 durante a diferenciação de Linfócitos T reguladores: a) Linfócitos T CD4+CD25- foram cultivados sob o estimulo policlonal (anti CD3/anti-CD28) na ausência (Th0) ou presença (Treg) de TGF- $\beta(0,3 \mathrm{ng} / \mathrm{ml})$. As células foram coletadas em tampão RIPA e analisada PFKFB3 em sua forma total e fosforilada, bem como a expressão de PFKFB3 durante a diferenciação de linfócitos T. b) Linfócitos T CD4+CD25- foram cultivados sob o estimulo policlonal (anti-CD3/anti-CD28) na presença (Treg) de TGF- $\beta(0,3 \mathrm{ng} / \mathrm{mL})$. As células foram coletadas em 48 horas de cultura, fixadas e permeabilizadas em laminas. As células foram incubadas com anticorpos primários contra FOXP3 e PFKFB3 (overnight; 4oC). Anticorpos secundários conjugados a fluoroforos foram adicionados. Lamínulas foram montadas com meio de montagem contendo DAPI (marcador nuclear). Imagens foram adquiridas em microscópio confocal e analisadas no software ImageJ. 


\subsection{A InIBIÇÃo dA ENZIMA PFKFB3 EM CÉlULAS T REGULADORAS É CAPAZ GERAR ACÚMULOS DE PROTEÍNAS O-GLUCONACILADAS}

Sabendo-se que a enzima PFKFB3 é expressa durante a diferenciação de Tregs, sendo esta capaz controlar o fluxo glicolítico e que os níveis de Ogluconilização são importantes para a função, estabilidade e diferenciação dessas células (Melo et al., 2019 em preparo) e de Foxp3 (Liu, B. et al., 2019). Consideramos a hipótese do presente trabalho, de que ao inibir a enzima PFKFB3 pode ocorrer uma diminuição do fluxo de moléculas que seguem para a via glicolítica e dessa forma gerar acumulo metabolítos em vias alternativas, como a das hexosaminas (Figura 3). Portanto, analisamos se ao inibir a enzima na cultura de Tregs com a ação da droga farmacológica 3PO $3 \mu \mathrm{M}$, que é inibidor da enzima PFKFB3 por $72 \mathrm{~h}$, era o suficiente para gerar acúmulos de proteínas O-gluconaciladas.

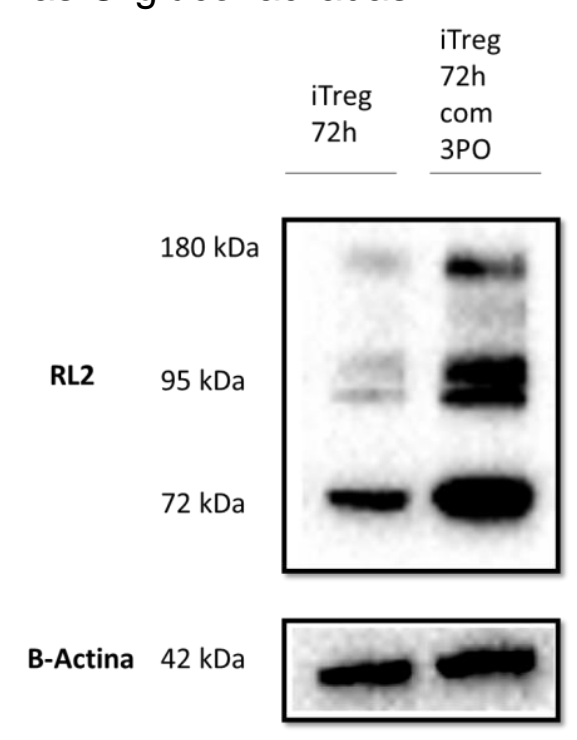

Figura 6 - Expressão proteica de PFKFB3 durante a diferenciação de Linfócitos T reguladores: Linfócitos T CD4+CD25- foram cultivados sob o estimulo policlonal (anti-CD3/anti-CD28) e TGF- $\beta$ $(0,3 \mathrm{ng} / \mathrm{ml})($ Treg) e na presença de $3 \mathrm{PO}(3 \mu \mathrm{g} / \mathrm{ml})$ por $72 \mathrm{~h}$. As células foram coletadas em tampão RIPA e analisadas as proteínas O-gluconaciladas (RL2) em sua forma total e fosforilada 
Para isso coletamos células de uma cultura de linfócitos que permaneceram na presença TGF- $\beta$ e (ou) na presença de 3PO por 72h para Western Blot e verificamos a presença de proteínas O-gluconaciladas através do anticorpo RL2 (Figura 6). Corroborando com a nossa hipótese, observamos um aumento de proteínas que sofreram a modificação pós-traducional no grupo em que houve exposição a droga inibidora da enzima PFKFB3.

\subsection{A INIBIÇÃo dA ENZIMA PFKFB3 GERA AUMENTO NA DIFERENCIAÇÃo dE CÉLULAS T REGULADORAS.}

Nos experimentos anteriores nós demonstramos que a enzima PFKFB3 é expressa nos momentos iniciais de células Treg e que existe um acúmulo de proteínas de O-gluconaciladas quando a enzima é inibida por 3PO. Portanto, o próximo passo foi avaliar a diferenciação de Tregs quando existe a inibição da enzima PFKFB3. Para verificarmos isso, linfócitos naïve foram isolados inseridos em cultura na presença dos seguintes estímulos: Anti-CD3/CD28 apenas (Th0); Anti-CD3/CD28 e TGF- $\beta$ (Treg) e também foi feita uma curva em 3 diferentes concentrações $(0,3 ; 1,3 \mu \mathrm{M})$ de duas drogas inibidoras de PFKFB3 (3PO e YZ9) (Figura 7). Essas células permaneceram em cultura por $72 \mathrm{~h}$ e foi verificado a expressão de Foxp3 em cada um dos grupos através de citometria de fluxo. Interessantemente, verificamos que tanto 3PO como YZ9 ao inibirem a enzima PFKFB3 geraram aumento da expressão de FOXP3 em todas as concentrações, em especial as concentrações de $1 \mu \mathrm{M}$ e $3 \mu \mathrm{M}$ que geraram diferenças significativas na diferenciação destas células. Sugerindo que a enzima PFKFB3 pode ter um papel de restringir a diferenciação de células Tregs, por manter 
o fluxo glicolítico dessas células em alta em seus estágios iniciais de diferenciação, sendo o motivo e mecanismo ainda desconhecido.
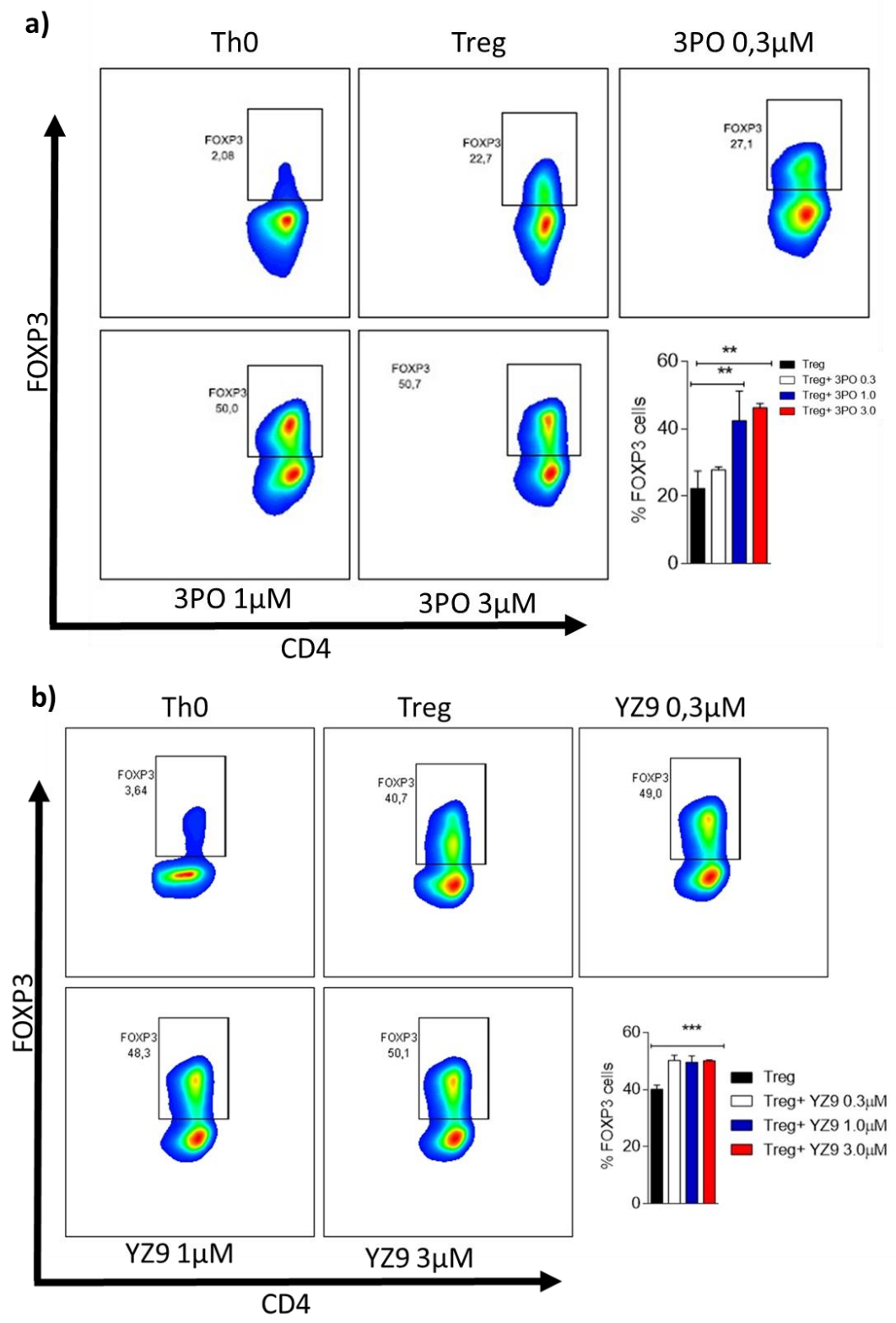

Figura 7 - A inibição da enzima PFKFB3 é capaz de gerar maior diferenciação de células T reguladoras: Linfócitos $T$ CD4+CD25- provenientes de animais $\mathrm{C} 57 \mathrm{BL} / 6$ foram isolados e cultivados sob condições polarizantes para Treg na ausência ou presença de a) $3 P O(0,3,1$ ou $3 \mu \mathrm{M})$ ou b) YZ9 $(0,3,1$ ou $3 \mu \mathrm{M})$, ambos inibidores de PFKFB3, por 96 horas. Após esse período, as células foram marcadas com um marcador de viabilidade (Fixable viability Dye) e os anticorpos anti-CD4 e anti-Foxp3. Os dados foram adquiridos no aparelho FACS Verse (BD Biosciences) e analisados por meio do programa Flowjow X. Os resultados estão expressos em Média \pm E.P.M. ${ }^{*} P<0,01{ }^{* * *} P<0,001$. Tendo sido analisados através da ANOVA de uma via, seguida pelo teste de Tukey. 
Após esses experimentos, fomos atrás de verificar se essa inibição da enzima PFKFB3 e aumento de diferenciação de Tregs está correlacionada com o acúmulo de proteínas O-gluconaciladas devido ao que foi observado no experimento da figura 6 deste trabalho. Nesse sentido, utilizamos da ferramenta farmacológica BADGP, um inibidor de OGT, a enzima responsável pela adição de UDP-GlucNAc em proteínas com a premissa de que a inibição de PFKFB3 simultânea a ela seria incapaz de gerar

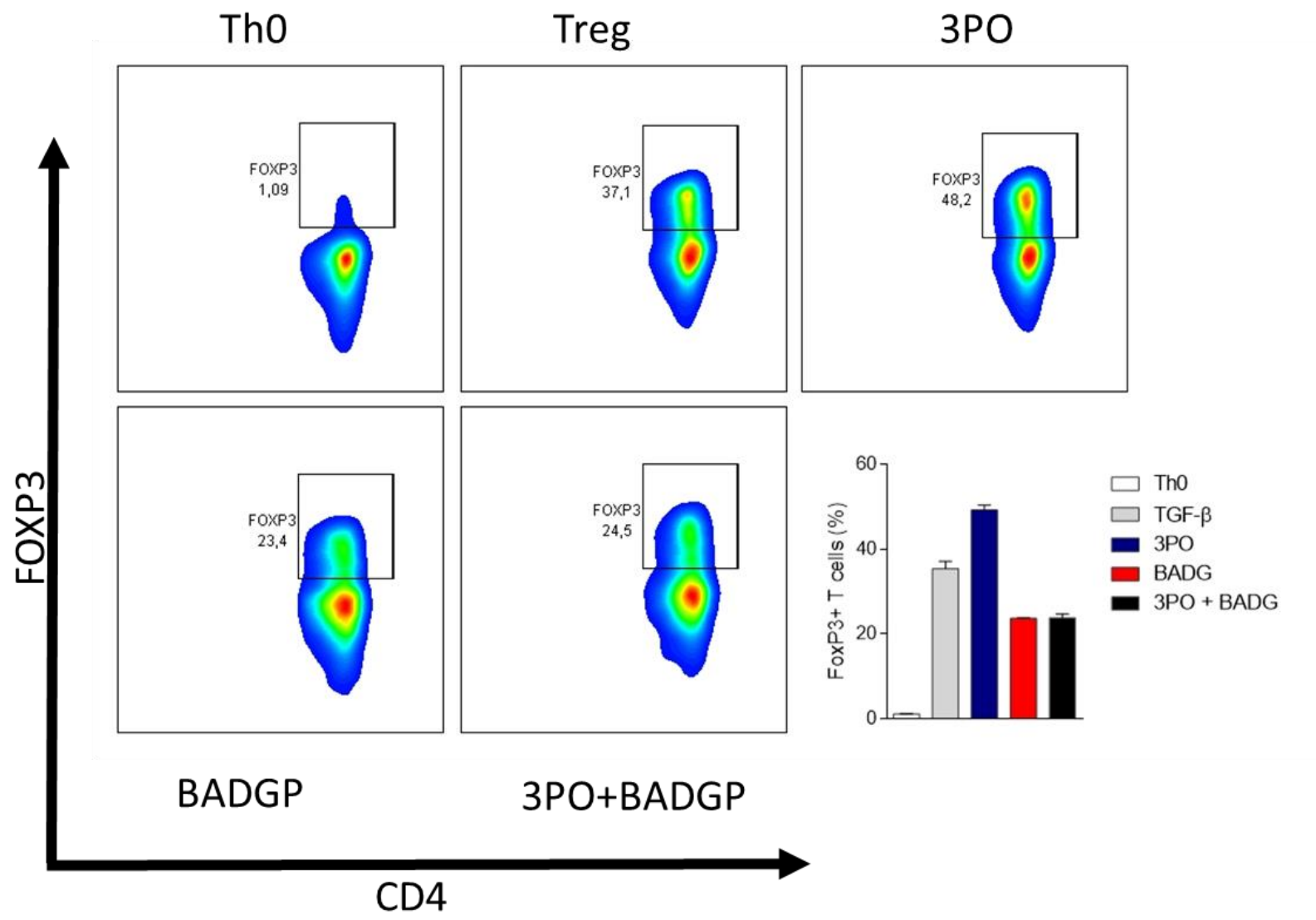

Figura 8 - A inibição da enzima PFKFB3 é capaz de gerar maior diferenciação de células T reguladoras e este efeito é dependente do aumento de O-gluconalização: Linfócitos T CD4+CD25provenientes de animais $\mathrm{C} 57 \mathrm{BL} / 6$ foram isolados e cultivados sob condições polarizantes para Treg na ausência ou presença de 3PO $(3 \mu \mathrm{M})$ o inibidor de PFKFB3; BADGP $(10 \mu \mathrm{M})$ inibidor de Ogluconacilação ou as duas drogas simultaneamente, por 96 horas. Após esse período, as células foram marcadas com um marcador de viabilidade (Fixable viability Dye) e os anticorpos anti-CD4 e anti-Foxp3. Os dados foram adquiridos no aparelho FACS Verse (BD Biosciences) e analisados por meio do programa Flowjow X.

maior expressão de Foxp3 (Figura 8). Para este experimento linfócitos T naïve foram colocados na presença dos seguintes estímulos: Somente anti-CD3/CD28 (Th0); AntiCD3/CD28 e TGF- $\beta$ (Treg) na presença ou não de 3PO e BADGP e na presença dos 
dois simultaneamente. Corroborando com nossos dados anteriores e hipótese do presente trabalho, foi observado que a inibição de PFKFB3 foi capaz de gerar o aumento da diferenciação de Tregs, no entanto, o efeito da droga é perdido quando utilizado em conjunto com o inibidor de OGT.

\subsection{A expressão de PFKFB3 É aumentada durante $O$ modelo de ENCEFALOMIELITE AUTOIMUNE EXPERIMENTAL}

Após demonstrarmos alguns aspectos quanto o papel da PFKFB3 em células Tregs, buscamos também analisar se essa enzima tem envolvimento no modelo de encefalomielite autoimune experimental (EAE) para que posteriormente pudéssemos explorar a terapêutica com 3PO, considerando que, de acordo com nossa hipotese talvez este tratamento possa levar a um aumento da população de Tregs e consequentemente suprimir a doença. Portanto, analisamos a expressão de PFKFB3 durante o modelo de EAE imunizando camundongos C57BL/6 com MOG35-55 em CFA para indução do modelo e coletamos linfonodos e medula espinhal durante diferentes dias/estágios da doença (dia 5, dia 10, dia 15, dia 20) para avaliar a expressão gênica de PFKFB3. Além disso, também coletamos a medula espinhal para Western Blot no pico da doença (dia 15) e verificar a expressão proteica de PFKFB3 (Figura 9).

Considerando que a enzima PFKFB3 necessita de estímulos para sua expressão, incluindo inflamatórios (Marsin, A. S. et al., 2002) era esperado seu aumento ao menos no pico da doença. A amplificação da expressão gênica de PFKFB3 foi observada no dia 15 (pico da doença) e também no dia 20 tanto em expressão gênica em linfonodos e medula espinha (Figura 9a e 9b) e em nível proteico na medula dos animais com a doença induzida após 15 dias (Figura 9c). 
Sugerindo que a enzima PFKFB3 tenha sua participação no avanço da doença e sendo um assim um potencial alvo terapêutico.

a)

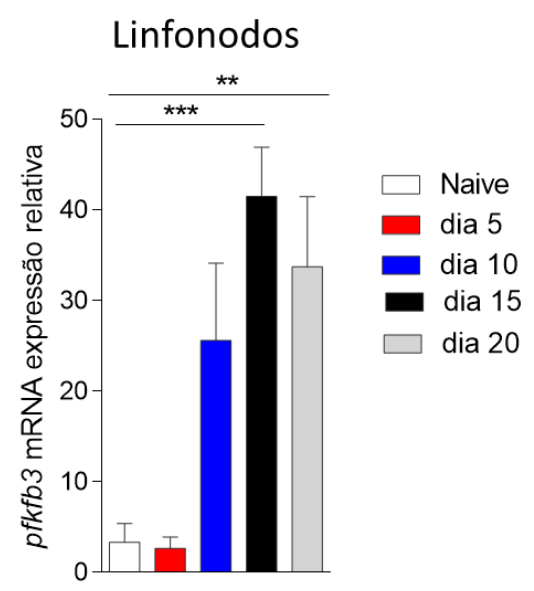

b)

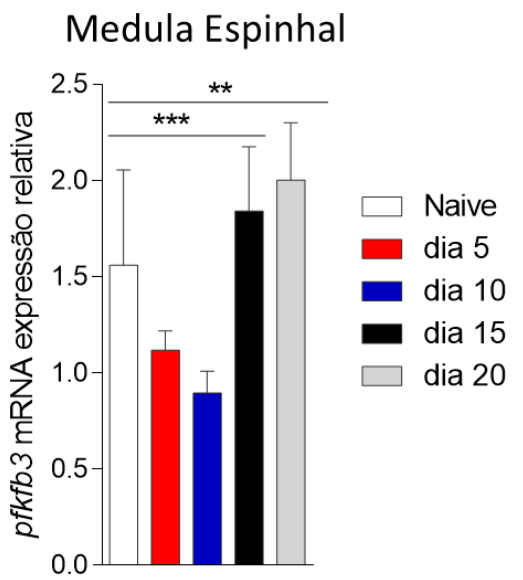

c)

Medula Espinhal - Pico da doença (dia 15)

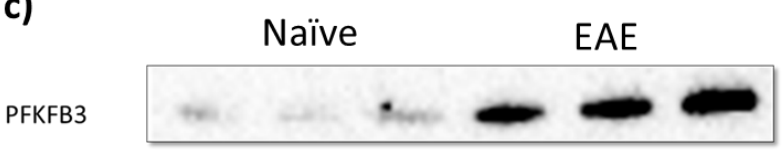

Figura 9 - A expressão de PFKFB3 é aumentada durante o modelo de EAE: Animais C57BL/6 foram imunizados com $300 \mu \mathrm{g}$ de MOG35-55 por via subcutânea em conjunto com Adjuvante Completo de Freund (CFA; $5 \mathrm{mg} / \mathrm{mL}$ de Mycobacterium tuberculosis H37RA) e receberam tratamento com toxina pertussis (200 ng/animal, via i.p.) nos dias 0 e 2 após a imunização. a) Linfonodos inguinais, cervicais e b) medula espinhal foram coletados para a extração de RNA em diferentes dias após a indução do modelo de EAE (dia 5,10,15,20) e realizado o qPCR Foi utilizado o grupo naïve como calibrador para a análise, sendo os resultados analisados através do método 2- $\triangle \Delta C T$, com correção da expressão genica realizada pela expressão de Gapdh. Os resultados foram obtidos por ANOVA de duas vias, seguida pelo teste de Tukey. Dados estão expressos em Média \pm E.P.M. ${ }^{* *} P<0,010{ }^{* \star *} P<0,001$. c) medula espinal foi retirada 15 dias após a imunização e avaliada a expressão PFKFB3 por Western Blot Blotting.

\subsection{O Tratamento com inibidor de PFKFB3 é capaz de Reduzir os sinais CLÍNICOS DO MODELO DE ENCEFALOMIELITE AUTOIMUNE EXPERIMENTAL}

Com o intuito de uma abordagem terapêutica, animais C57BL/6 que sofreram indução do modelo de EAE através da imunização com MOG35-55 em CFA foram tratados com 3PO $(25 \mathrm{mg} / \mathrm{Kg})$ e salina a partir do $6^{\circ}$ dia até o $14^{\circ}$ dia do modelo, Estes animais foram avaliados através de um escore clínico por observação visual de sintomas até $021^{\circ}$ dia após o início do modelo e observou-se que os animais que foram submetidos ao tratamento diário com inibidor de PFKFB3 mostraram-se mais 
resistentes a progressão da doença quando comparado aos animais tratados com o veículo (Figura 10). Além disso, foi observado uma redução do infiltrado inflamatório

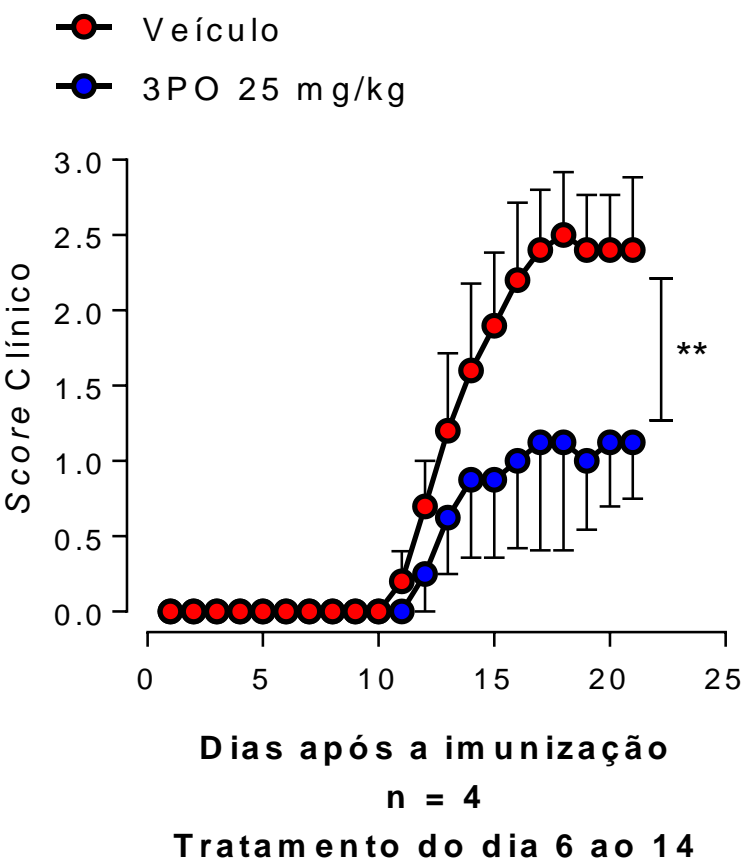

Figura 10 - Tratamento com inibidor de PFKFB3 é capaz de reduzir os sinais clínicos do modelo de EAE: Animais C57BL/6 foram imunizados com 300 g de MOG35-55 por via subcutânea em conjunto com Adjuvante Completo de Freund (CFA; $5 \mathrm{mg} / \mathrm{mL}$ de Mycobacterium tuberculosis H37RA) e receberam tratamento com toxina pertussis ( $200 \mathrm{ng} / \mathrm{animal}$, via i.p.) nos dias 0 e 2 após a imunização. O grupo controle foi tratado com veículo (salina) e o outro com $3 \mathrm{PO}(25 \mathrm{mg} / \mathrm{Kg}$; via i.p.). O escore clinico foi avaliado. Resultados expressos em Média \pm E.P.M e analisados através de ANOVA de duas vias, seguido do teste de Bonferroni. ${ }^{* *} \mathrm{P}<0,01$.

na medula dos animais tratados com 3PO (Figura 11a) nas lâminas de HE e diminuição da degradação de mielina (Figura 11b) através do corante Fluormyelin, específico para florescência em mielina. No entanto, ao coletarmos os linfonodos dos diferentes grupos para a citometria de fluxo, não foi verificado uma maior diferenciação de células Tregs (Figura 12). Porém, quanto a este resultado, o modelo de EAE é divido em dias após a imunização, teoricamente o pico da doença é entre o $14^{\circ}$ dia após a imunização até o $16^{\circ}$, após isso ocorre uma melhora dos animais, podendo ser essa a causa da expressão de Foxp3 estar em igualdade com os linfonodos 
de animais não tratados com inibidor de 3PO. Necessitando de novos experimentos para avaliar este evento.

a)

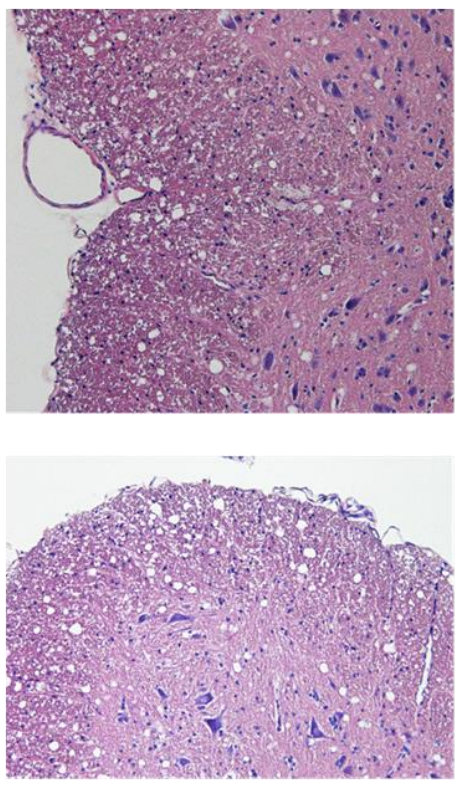

NAIVE
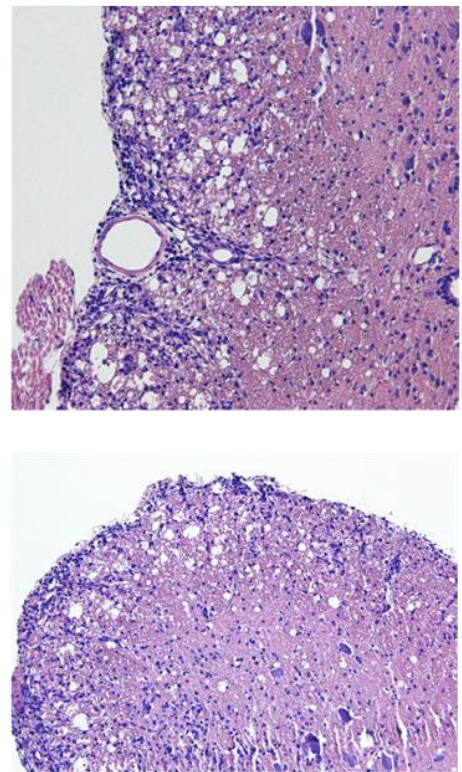

$E A E-N A ̃ O$ TRATADO
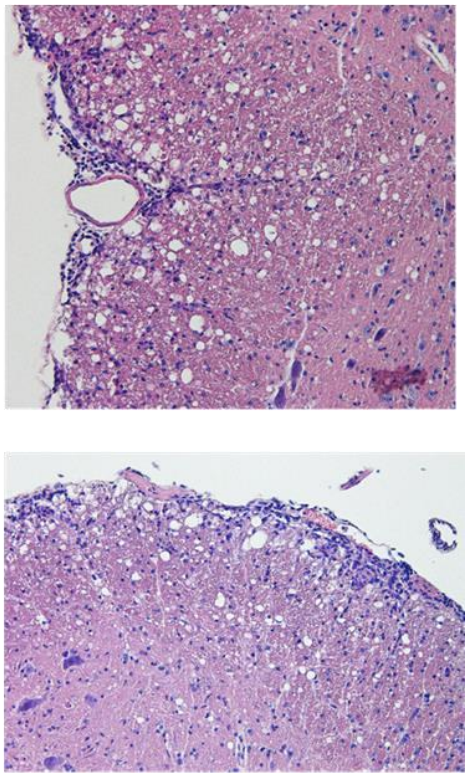

$E A E-3 P O$

b)

\section{EAE - NÃO TRATADO}

$E A E-3 P O$
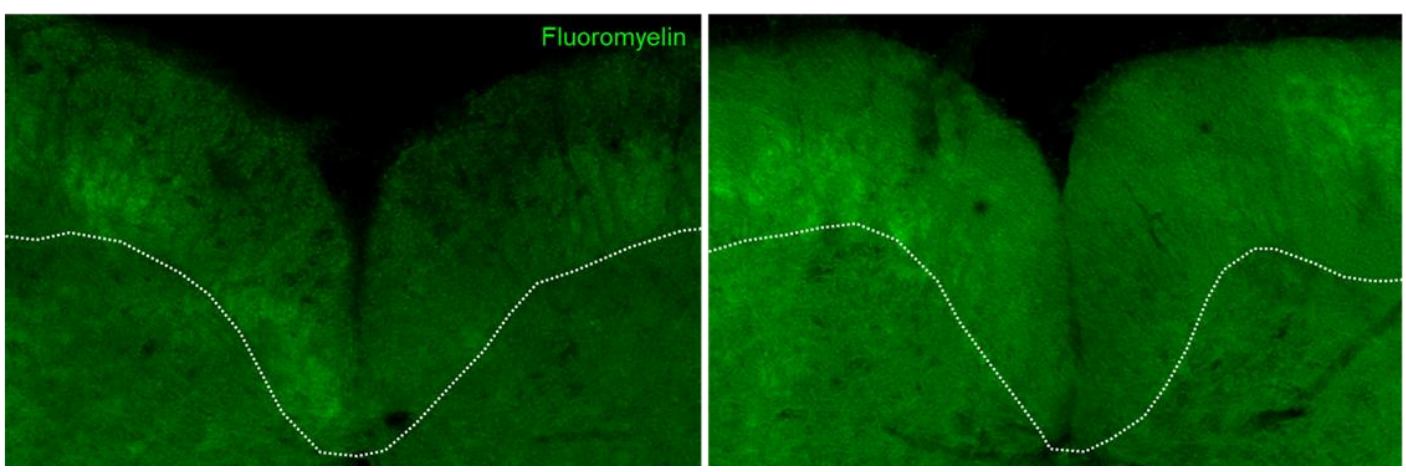

Figura 11 - 0 tratamento com inibidor de 3PO é capaz de reduzir o infiltrado inflamatório e degradação da mielina no modelo de EAE: Animais C57BL/6 foram imunizados com $300 \mu \mathrm{g}$ de MOG35-55 por via subcutânea em conjunto com Adjuvante Completo de Freund (CFA; $5 \mathrm{mg} / \mathrm{mL}$ de Mycobacterium tuberculosis H37RA) e receberam tratamento com toxina pertussis (200 ng/animal, via i.p.) nos dias 0 e 2 após a imunização. O grupo controle foi tratado com veículo (salina) e o outro com 3 PO (25mg/Kg; via s.c.). A medula foi retirada 21 dias após a imunização e avaliado a) $O$ infiltrado inflamatório por coloração Hematoxilina-Eosina (HE) e b) degradação da mielina por fluorescência específica (Fluormyelin). 

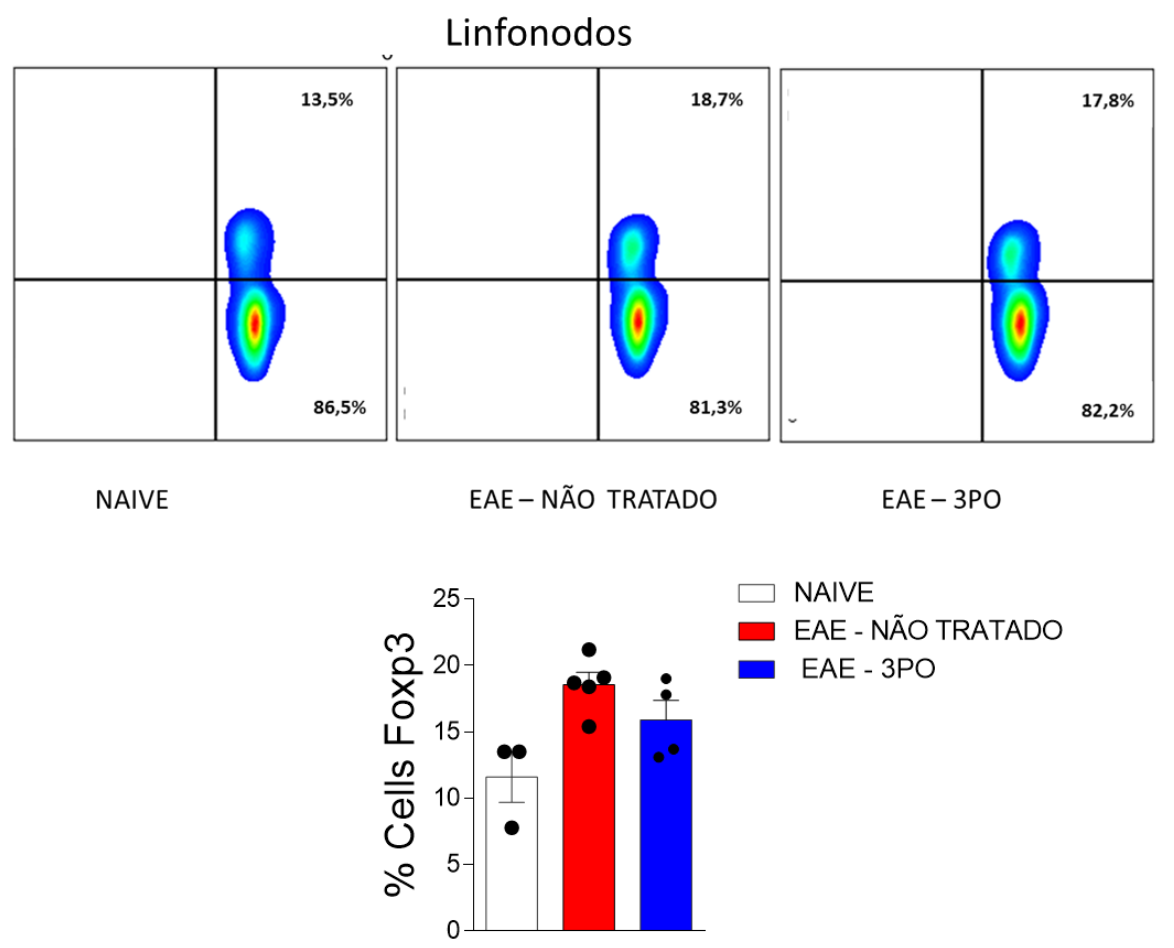

Figura 12 - A diferenciação de Tregs não é aumentada nos linfonodos de animais tratados com inibidor de PFKFB3 no 21 dia após a indução de EAE: Animais C57BL/6 foram imunizados com $300 \mu \mathrm{g}$ de MOG35-55 por via subcutânea em conjunto com Adjuvante Completo de Freund (CFA; 5 $\mathrm{mg} / \mathrm{mL}$ de Mycobacterium tuberculosis H37RA) e receberam tratamento com toxina pertussis (200 ng/animal, via i.p.) nos dias 0 e 2 após a imunização. O grupo controle foi tratado com veículo (salina) e o outro com 3PO (25mg/Kg; via s.c.). Linfonodos inguinais e cervicais dos animais foram coletados macerados e as células foram marcadas com um marcador de viabilidade (Fixable viability Dye) e os anticorpos anti-CD4 e anti-Foxp3. Os dados foram adquiridos no aparelho FACS Verse (BD Biosciences) e analisados por meio do programa Flowjow X.

\section{DISCUSSÃO}

Atualmente estudos de metabolismo de linfócitos $\mathrm{T}$ tem postulado dois perfis metabólicos antagonicos, sendo um deles o de células T efetoras (Th1 Th2 Th17) utilizando de um intenso estado de anabolismo dependente de glicólise anaeróbica (Amersfoort e Kuiper, 2017), altamente regulados principalmente pela ativação da via $\mathrm{PI} 3 \mathrm{~K} / \mathrm{Akt} / \mathrm{mTOR}$ e de fatores de transcrição como HIF-1a e c-Myc (Ananieva et al., 2014; Palazon et al., 2014). Diferentemente do perfil citado anteriormente, Tregs por sua vez possuem outro perfil metabólico, elas apresentam pouca necessidade de 
utilização da via glicolítica e fazem uso de ácidos graxos como principais substratos para as reações necessárias para desempenhar suas funções (Klysz et al., 2015). Entretanto, recentemente, tem sido demonstrado que essas duas vias metabólicas não são generalizadas, a exemplo disso temos trabalhos recentes que observaram que a inibição da enzima HK, porta de entrada da via glicolítica sendo capaz de diminuir a expressão de Foxp3 (De La Rosa et al., 2004). Tregs também já comprovaram ter a capacidade de se reprogramar em ambientes ricos em lactato e com escassez glicose adquirindo energia através de fosforilação oxidativa e via das pentoses (Angelin et al., 2017). Além disso, vias metabólicas alternativas como a das hexosaminas também já demonstraram ter sua importância na expressão Foxp3 (Liu, Bing et al., 2019; Machacek et al., 2019).

Neste sentido, este trabalho buscou contribuir com o entendimento do papel de da enzima PFKFB3 no metabolismo de células T reguladoras, uma enzima muito importante para o fluxo de glicose na via glicolítica, sendo este o primeiro a investigar tal papel em Tregs. Primeiramente, demonstramos que a expressão da enzima PFKFB3 possui o seu pico de expressão nos estágios iniciais da diferenciação de Tregs (expressão gênica em 12h e proteica 24h), quanto a estes resultados, já havia sido demonstrado que os estímulos de anti-CD3/CD28 por si só era capaz de promover o aumento da expressão da enzima PFKFB3 através da via PI3k/Akt (Telang, Sucheta et al., 2012). Entretanto, em nossos experimentos o estímulo de TGF- $\beta$ em células T demonstrou inibir essa expressão. Interessantemente, sabe se que a expressão de FoxP3 é capaz de gerar aumento de PTEN, e esta proteína reduz a ativação de PI3k/Akt (Buckler et al., 2006), que também já demonstrou no contexto de tumores que pode inibir a enzima PFKFB3 (Garcia-Cao et al., 2012), corroborando assim com nossos resultados. No entanto, TGF- $\beta$ também já foi descrito como 
estímulo que gerou aumento da expressão e atividade da enzima PFKFB3 via AMPK em células de glioblastoma (Rodriguez-Garcia et al., 2017). Sabendo-se que a AMPK é o principal regulador metabólico de Tregs (Michalek et al., 2011) e possuindo ligação com maior atividade e expressão de PFKFB3 (Bartrons, Rodríguez-García, et al., 2018), tornando assim necessário novos trabalhos e experimentos para melhor elucidação de como é a regulação de PFKFB3 por AMPK em células Tregs, já que o que foi observado em nossos experimentos é que houve redução e não aumento da expressão por TGF- $\beta$.

Quanto ao fluxo glicolítico, sabe se que é em grande parte definido por F2,6BP, que interage PFK1 e é produzido em larga escala pela enzima PFKFB3 (Moncada et al., 2012). Portanto, nosso próximo passo foi verificar os efeitos da inibição dessa enzima em Tregs. Interessantemente, observamos que a inibição da enzima em 72h de cultura em condições polarizantes para Treg foi capaz de gerar acumulo de proteínas O-gluconaciladas, corroborando com a hipótese proposta neste trabalho. No entanto, não chegamos a dosar outros metabólitos intermediários importantes para confirmamos tal hipótese.

Também observamos que a inibição através de duas ferramentas farmacológicas diferentes (3PO e YZ9) proporcionou uma maior diferenciação de Tregs em 3 concentrações diferentes. Estes resultados demonstram que a enzima pode restringir a diferenciação de células T reguladoras sendo este o primeiro trabalho a demonstrar tal mecanismo. Além disso, considerando trabalhos atuais em que a Ogluconalização demonstrou ter papel importante para a expressão de Foxp3 (Liu, Bing et al., 2019; Machacek et al., 2019) e que houve aumento de proteínas Ogluconaciladas na cultura de Tregs na presença do inibidor de PFKFB3 acompanhado de uma maior diferenciação dessas células. Sugerimos novamente que moléculas 
possam estar sendo acumuladas e direcionadas para a via das hexosaminas, assim como havíamos previsto em nossa hipótese, pois resultados do nosso laboratório já haviam demonstrado que Tregs utilizam da via das hexosaminas tanto em suas diferenciações, funções e estabilidades, inclusive demonstraram que a inibição dessa via é capaz de restringir a diferenciação de células T reguladoras (Melo et al., 2019 em preparo).

Portanto, para comprovar essa ligação entre o aumento de diferenciação de Tregs e acúmulo de proteínas O-gluconaciladas através da inibição da enzima PFKFB3, foi feita uma cultura de linfócitos com estímulos polarizantes para Tregs na presença de inibidor de PFKFB3 (3PO), inibidor de OGT (BADGP) e as duas drogas simultaneamente (3PO+BADGP) durante a diferenciação dessas células por 72h. Através deste experimento, observamos que houve o aumento da expressão de Foxp3 quando os linfócitos estavam na presença de 3PO e uma diminuição na presença de BADGP, sendo este último evento já demonstrado por colaboradores do nosso grupo (Melo et al., 2019 em preparo), exemplificando a importância da Ogluconilização em células Tregs. Porém, quando linfócitos se diferenciaram na presença de TGF- $\beta$, 3PO e BADGP simultaneamente, não houve aumento da expressão de FOXP3, de fato elas obtiveram uma expressão de Foxp3 análoga ao das células Tregs expostas ao BADGP apenas corroborando com nossa teoria de que o aumento da diferenciação pela inibição de PFKFB3 estava ligado ao acúmulo de proteínas O-gluconacilas visto em experimentos anteriores. Entretanto, novos experimentos têm de ser feito para comprovar tal mecanismo proposto.

Após adquirirmos resultados sobre células T reguladoras e a enzima PFKFB3 partimos para o intuito de analisarmos o potencial terapêutico desta enzima no contexto da autoimunidade. Nesse contexto, a inibição de PFKFB3 já demonstrou 
gerar melhora em modelos de doença enxerto vs hospedeiro (Nguyen et al., 2016) e em um modelo de psoríase, suprimindo a imunidade dependente de células $\mathrm{T}$ in vivo (Telang, S. et al., 2012). Porém, nada se tem do tratamento com 3PO no modelo de $E A E$, além disso acreditamos que essa maior proteção em modelos de autoimunes e inflamatórios seja pelo mecanismo de que a PFKFB3 inibida poderia garantir uma maior diferenciação de Tregs e consequentemente, suprimir a resposta do EAE.

Para verificar se a enzima possui potencial terapêutico, imunizamos animais para o modelo de EAE e coletamos linfonodos e medula espinhal destes para verificar a expressão gênica de PFKFB3 em diferentes dias/ estágios da doença (dia 5,10,15 e 20) após o início do modelo. A enzima PFKFB3 foi observada tendo uma maior expressão gênica tanto em linfonodos como em medula espinhal nos $15^{\circ}$ e $20^{\circ}$ dia do modelo de EAE. A medula espinhal de animais imunizados para o EAE também foi coletada para Western Blot no pico da doença onde também observamos uma maior expressão de PFKFB3, sugerindo que a enzima possui participação na resposta do modelo e pode ser um potencial alvo terapêutico para doenças inflamatória autoimunes. Quanto a este resultado vale ressaltar que o aumento da enzima PFKFB3 durante o modelo era esperado, considerando que diferentes estímulos inflamatórios (Marsin, A. S. et al., 2002), incluindo IL-6 (Bartrons, Simon-Molas, et al., 2018) são capazes de causar estímulo para maior produção dessa enzima. Considerando também que o modelo EAE é baseado em uma resposta de linfócitos Th1/Th17 auto reativos que proporcionam um aumento de estímulos inflamatórios e também da citocina IL-6 (Okuda et al., 1999).

Por estarmos analisando o papel da enzima PFKFB3 em células Tregs, Nossa teoria seria que, tratando animais neste modelo com 3PO, conseguiríamos um aumento de células Tregs por potencializar a via das hexosaminas que por sua vez, 
seriam capazes de amenizar essa resposta por mecanismos de supressão e potencialização desse subtipo celular. Portanto, após verificarmos que a expressão da enzima é aumentada no decorrer da doença induzida pelo modelo de EAE, buscamos opções de tratamento com 3PO na literatura e utilizamos um protocolo customizado inspirado no trabalho de Telang e colaboradores (Telang, S. et al., 2012), que utilizaram 3PO como tratamento para psoríase. Sendo assim, imunizamos camundongos C57BL/6 com MOG $35-55$ em CFA para indução do modelo e tratamos

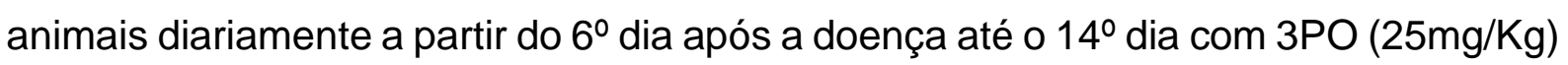
ou um veículo (Salina). Durante o decorrer do modelo os sinais clínicos desses dois grupos foram avaliados diariamente e os camundongos tratados com 3PO demonstraram ter um desenvolvimento mais brando da doença, também foi observado um menor infiltrado inflamatório e menor degradação da mielina destes animais. Entretanto, quando fomos analisar os linfonodos destes animais não verificamos um aumento de Foxp3 nos linfonodos destes animais, podendo ser indicativo que a proteção gerada por 3PO não ocorreu através da maior produção de Tregs durante a doença.

Quanto a este último experimento, O modelo de EAE possui diferentes estágios, possuindo estágio inicial, pico da doença, logo após isso ocorre uma melhora dos animais (Hiltensperger e Korn, 2018). Nos coletamos os linfonodos no dia $21^{\circ}$, onde os animais passam para o estágio em que ocorre o retrocesso da resposta do modelo de EAE e uma diminuição quanto aos sinais clínicos. Portanto, seria necessário repetir tal experimento e analisarmos os linfonodos e outros parâmetros no início da imunização e também no pico da doença para avaliarmos melhor quanto ao fenômeno que proporcionou maior proteção aos camundongos tratados com 3PO. Independentemente disso, a inibição da enzima PFKFB3 no 
modelo de EAE demonstrou ser potencial alvo farmacológico para doenças autoimunes, corroborando com outros trabalhos que já verificaram tal evento (Telang, S. et al., 2012; Nguyen et al., 2016).

Contudo, todos resultados descritos anteriormente proporcionaram um maior conhecimento sobre a expressão da enzima PFKFB3 na T reguladora e que possui participação em sua diferenciação, no sentido de restringir sua diferenciação. Além disso nossos resultados também demonstraram que a inibição da enzima é capaz de garantir uma maior população de Tregs, gerar aumento de proteínas O-gluconaciladas e que talvez esses eventos possam estar interligados. Também observamos que 3PO, o inibidor de PFKFB3 garante maior proteção em camundongos imunizados no modelo de EAE. Entretanto, novos estudos como e devem ser feitos para melhor caracterização de enzima PFKFB3 em células $T$ reguladoras e no modelo de EAE para melhor compreensão dos eventos observados nesse trabalho

\section{Conclusão}

O estudo demonstrou que a enzima PFKFB3 é expressa na diferenciação de células $\mathrm{T}$ reguladoras nos estágios iniciais e possui o papel regulador, capaz de restringir a diferenciação desse subtipo celular por um mecanismo ainda desconhecido. Além disso, a inibição da enzima PFKFB3 demonstrou potencializar a diferenciação de $\mathrm{T}$ reguladoras in vitro e pode gerar acúmulos de proteínas Ogluconaciladas. Foi evidenciado ainda que a inibição da enzima PFKFB3 no modelo de encefalomielite autoimune experimental proporcionou uma maior proteção a animais imunizados. Portanto, a PFKFB3 tem se mostrado um potencial alvo farmacológico para o tratamento de doenças inflamatórias autoimunes. 


\section{REFERÊNCIAS BIBLIOGRÁFICAS}

AKELLA, N. M.; CIRAKU, L.; REGINATO, M. J. Fueling the fire: emerging role of the hexosamine biosynthetic pathway in cancer. BMC Biol, v. 17, n. 1, p. 52, Jul 42019. ISSN 1741-7007

ALMEIDA, L. et al. Metabolic pathways in T cell activation and lineage differentiation. Semin Immunol, v. 28, n. 5, p. 514-524, Oct 2016. ISSN 1096-3618

AMERSFOORT, J.; KUIPER, J. T cell metabolism in metabolic disease-associated autoimmunity. Immunobiology, v. 222, n. 10, p. 925-936, Oct 2017. ISSN 1878-3279

ANANIEVA, E. A. et al. Cytosolic branched chain aminotransferase (BCATc) regulates mTORC1 signaling and glycolytic metabolism in CD4+ T cells. J Biol Chem, v. 289, n. 27, p. 18793-804, Jul 4 2014. ISSN 1083-351X

ANGELIN, A. et al. Foxp3 Reprograms T Cell Metabolism to Function in Low-Glucose, High-Lactate Environments. Cell Metab, v. 25, n. 6, p. $1282-1293$ e7, Jun 62017.

APOSTOLOU, I.; VON BOEHMER, H. In vivo instruction of suppressor commitment in naive T cells. J Exp Med, v. 199, n. 10, p. 1401-8, May 17 2004. ISSN 0022-1007

BARTRONS, R.; CARO, J. Hypoxia, glucose metabolism and the Warburg's effect. Journal of Bioenergetics and Biomembranes, v. 39, n. 3, p. 223-229, 2007. ISSN 0145-479X1573-6881.

BARTRONS, R. et al. The potential utility of PFKFB3 as a therapeutic target. Expert Opinion on Therapeutic Targets, v. 22, n. 8, p. 659-674, 2018. ISSN 1472-8222 1744-7631.

BARTRONS, R. et al. Fructose 2,6-Bisphosphate in Cancer Cell Metabolism. Frontiers in Oncology, v. 8, 2018. ISSN 2234-943X.

BOND, M. R.; HANOVER, J. A. A little sugar goes a long way: The cell biology of OGlcNAc. The Journal of Cell Biology, v. 208, n. 7, p. 869-880, 2015. ISSN 0021 95251540-8140.

BONILLA, F. A.; OETTGEN, H. C. Adaptive immunity. J Allergy Clin Immunol, v. 125, n. 2 Suppl 2, p. S33-40, Feb 2010. ISSN 1097-6825 (Electronic) 0091-6749

BOPP, T. et al. Cyclic adenosine monophosphate is a key component of regulatory $T$ cell-mediated suppression. J Exp Med, v. 204, n. 6, p. 1303-10, Jun 11 2007. ISSN 0022-1007 
BUCKLER, J. L. et al. Cutting Edge: T Cell Requirement for CD28 Costimulation Is Due to Negative Regulation of TCR Signals by PTEN. The Journal of Immunology, v. 177, n. 7, p. 4262-4266, 2006. ISSN 0022-17671550-6606.

BUSE, M. G. Hexosamines, insulin resistance, and the complications of diabetes: current status. American Journal of Physiology-Endocrinology and Metabolism, v. 290, n. 1, p. E1-E8, 2006. ISSN 0193-18491522-1555.

CHESNEY, J. 6-phosphofructo-2-kinase/fructose-2,6-bisphosphatase and tumor cell glycolysis. Curr Opin Clin Nutr Metab Care, v. 9, n. 5, p. 535-9, Sep 2006. ISSN 1363-1950

$\mathrm{CHI}, \mathrm{H}$. Regulation and function of mTOR signalling in T cell fate decisions. Nat Rev Immunol, v. 12, n. 5, p. 325-38, Apr 20 2012. ISSN 1474-1741 (Electronic) 1474-1733

CHISOLM, D. A.; WEINMANN, A. S. TCR-Signaling Events in Cellular Metabolism and Specialization. Front Immunol, v. 6, p. 292, 2015. ISSN 1664-3224 (Print) 1664-3224

DE LA ROSA, M. et al. Interleukin-2 is essential for CD4+CD25+ regulatory T cell function. European Journal of Immunology, v. 34, n. 9, p. 2480-2488, 2004. ISSN 0014-29801521-4141.

DIMELOE, S. et al. T-cell metabolism governing activation, proliferation and differentiation; a modular view. Immunology, v. 150, n. 1, p. 35-44, Jan 2017. ISSN 1365-2567

FOX, C. J.; HAMMERMAN, P. S.; THOMPSON, C. B. Fuel feeds function: energy metabolism and the T-cell response. Nat Rev Immunol, v. 5, n. 11, p. 844-52, Nov 2005. ISSN 1474-1733

FRAUWIRTH, K. A. et al. The CD28 signaling pathway regulates glucose metabolism. Immunity, v. 16, n. 6, p. 769-77, Jun 2002. ISSN 1074-7613 (Print) 1074-7613

FRAUWIRTH, K. A.; THOMPSON, C. B. Regulation of T lymphocyte metabolism. J Immunol, v. 172, n. 8, p. 4661-5, Apr 15 2004. ISSN 0022-1767 (Print) 0022-1767

GALGANI, M. et al. Role of Metabolism in the Immunobiology of Regulatory T Cells. J Immunol, v. 197, n. 7, p. 2567-75, Oct 1 2016. ISSN 1550-6606 (Electronic) 0022-1767

GARCIA-CAO, I. et al. Systemic elevation of PTEN induces a tumor-suppressive metabolic state. Cell, v. 149, n. 1, p. 49-62, Mar 30 2012. ISSN 1097-4172 (Electronic) 0092-8674 
GÉLINAS, R. et al. AMP-Activated Protein Kinase and O-GlcNAcylation, Two Partners Tightly Connected to Regulate Key Cellular Processes. Frontiers in Endocrinology, v. 9, 2018. ISSN 1664-2392.

GERRIETS, V. A. et al. Foxp3 and Toll-like receptor signaling balance Treg cell anabolic metabolism for suppression. Nat Immunol, v. 17, n. 12, p. 1459-1466, Dec 2016. ISSN 1529-2916

GRZES, K. M.; FIELD, C. S.; PEARCE, E. J. Treg Cells Survive and Thrive in Inhospitable Environments. Cell Metab, v. 25, n. 6, p. 1213-1215, Jun 6 2017. ISSN 1932-7420

HARWOOD, K. R.; HANOVER, J. A. Nutrient-driven O-GlcNAc cycling - think globally but act locally. Journal of Cell Science, v. 127, n. 9, p. 1857-1867, 2014. ISSN 0021 95331477-9137.

HILTENSPERGER, M.; KORN, T. The Interleukin (IL)-23/T helper (Th)17 Axis in Experimental Autoimmune Encephalomyelitis and Multiple Sclerosis. Cold Spring Harb Perspect Med, v. 8, n. 1, Jan 2 2018. ISSN 2157-1422 (Electronic)

2157-1422

HORI, S.; SAKAGUCHI, S. Foxp3: a critical regulator of the development and function of regulatory T cells. Microbes Infect, v. 6, n. 8, p. 745-51, Jul 2004. ISSN 1286-4579

HOUDDANE, A. et al. Role of Akt/PKB and PFKFB isoenzymes in the control of glycolysis, cell proliferation and protein synthesis in mitogen-stimulated thymocytes. Cell Signal, v. 34, p. 23-37, Jun 2017. ISSN 1873-3913 (Electronic)

0898-6568

HOWIE, D. et al. Foxp3 drives oxidative phosphorylation and protection from lipotoxicity. JCI Insight, v. 2, n. 3, 2017. ISSN 2379-3708.

HURTADO-GUERRERO, R.; DORFMUELLER, H. C.; VAN AALTEN, D. M. Molecular mechanisms of O-GlcNAcylation. Curr Opin Struct Biol, v. 18, n. 5, p. 551-7, Oct 2008. ISSN 0959-440X

HURTADO-GUERRERO, R. et al. Glucose-6-phosphate as a probe for the glucosamine-6-phosphateN-acetyltransferase Michaelis complex. FEBS Letters, v. 581, n. 29, p. 5597-5600, 2007. ISSN 00145793.

JACOBS, S. R. et al. Glucose Uptake Is Limiting in T Cell Activation and Requires CD28-Mediated Akt-Dependent and Independent Pathways. The Journal of Immunology, v. 180, n. 7, p. 4476-4486, 2008. ISSN 0022-17671550-6606.

JONES, R. G.; THOMPSON, C. B. Revving the engine: signal transduction fuels T cell activation. Immunity, v. 27, n. 2, p. 173-8, Aug 2007. ISSN 1074-7613 (Print) 1074-7613

KANAMORI, M. et al. Induced Regulatory T Cells: Their Development, Stability, and Applications. Trends Immunol, v. 37, n. 11, p. 803-811, Nov 2016. ISSN 1471-4981 
KIM, S. G. et al. Crystal structure of the hypoxia-inducible form of 6-phosphofructo-2kinase/fructose-2,6-bisphosphatase (PFKFB3): a possible new target for cancer therapy. J Biol Chem, v. 281, n. 5, p. 2939-44, Feb 3 2006. ISSN 0021-9258

KLYSZ, D. et al. Glutamine-dependent $\alpha$-ketoglutarate production regulates the balance between $T$ helper 1 cell and regulatory T cell generation. Science Signaling, v. 8, n. 396, p. ra97-ra97, 2015. ISSN 1945-08771937-9145.

$\mathrm{KOCH}, \mathrm{U}$;; RADTKE, F. Mechanisms of T cell development and transformation. Annu Rev Cell Dev Biol, v. 27, p. 539-62, 2011. ISSN 1530-8995 (Electronic)

1081-0706

LI, X.; ZHENG, Y. Regulatory T cell identity: formation and maintenance. Trends Immunol, v. 36, n. 6, p. 344-53, Jun 2015. ISSN 1471-4981 (Electronic)

1471-4906

LINKE, M. et al. mTORC1 and mTORC2 as regulators of cell metabolism in immunity. FEBS Letters, v. 591, n. 19, p. 3089-3103, 2017. ISSN 00145793.

LIU, B. et al. The lineage stability and suppressive program of regulatory $T$ cells require protein O-GlcNAcylation. Nature Communications, v. 10, n. 1, 2019. ISSN 2041-1723.

LIU, B. et al. The lineage stability and suppressive program of regulatory $T$ cells require protein O-GIcNAcylation. Nat Commun, v. 10, n. 1, p. 354, Jan 21 2019. ISSN 2041-1723

LUND, P. J.; ELIAS, J. E.; DAVIS, M. M. Global Analysis of O-GlcNAc Glycoproteins in Activated Human T Cells. The Journal of Immunology, v. 197, n. 8, p. 3086-3098, 2016. ISSN 0022-17671550-6606.

LUNT, S. Y.; VANDER HEIDEN, M. G. Aerobic glycolysis: meeting the metabolic requirements of cell proliferation. Annu Rev Cell Dev Biol, v. 27, p. 441-64, 2011. ISSN 1530-8995

MACHACEK, M. et al. Elevated O-GlcNAcylation enhances pro-inflammatory Th17 function by altering the intracellular lipid microenvironment. Journal of Biological Chemistry, v. 294, n. 22, p. 8973-8990, 2019. ISSN 0021-92581083-351X.

MAGENAU, J. M. et al. Frequency of CD4(+)CD25(hi)FOXP3(+) regulatory T cells has diagnostic and prognostic value as a biomarker for acute graft-versus-hostdisease. Biol Blood Marrow Transplant, v. 16, n. 7, p. 907-14, Jul 2010. ISSN 15236536

MARSIN, A.-S. et al. The Stimulation of Glycolysis by Hypoxia in Activated Monocytes Is Mediated by AMP-activated Protein Kinase and Inducible 6-Phosphofructo-2-kinase. Journal of Biological Chemistry, v. 277, n. 34, p. 30778-30783, 2002. ISSN 0021 9258 1083-351X. 
MARSIN, A. S. et al. The stimulation of glycolysis by hypoxia in activated monocytes is mediated by AMP-activated protein kinase and inducible 6-phosphofructo-2-kinase. J Biol Chem, v. 277, n. 34, p. 30778-83, Aug 23 2002. ISSN 0021-9258

MELLO, P. H. et al. Papel da via metabólica das hexosaminas e da OGlcNAcilação na diferenciação e estabilidade de Tregs. Tese de Doutorado - Departamento de Farmacologia da Faculdade de Medicina de Ribeirão Preto Departamento de Imunologia Básica e Aplicada da Faculdade de Medicina de Ribeirão Preto Universidade de São Paulo, Ribeirão Preto, SP. 2018.

MICHALEK, R. D. et al. Cutting edge: distinct glycolytic and lipid oxidative metabolic programs are essential for effector and regulatory CD4+ T cell subsets. J Immunol, v. 186, n. 6, p. 3299-303, Mar 15 2011. ISSN 1550-6606

MICHELS, P. A.; RIGDEN, D. J. Evolutionary analysis of fructose 2,6-bisphosphate metabolism. IUBMB Life, v. 58, n. 3, p. 133-41, Mar 2006. ISSN 1521-6543

MONCADA, S.; HIGGS, E. A.; COLOMBO, S. L. Fulfilling the metabolic requirements for cell proliferation. Biochem J, v. 446, n. 1, p. 1-7, Aug 15 2012. ISSN 1470-8728

NEMAZEE, D. Receptor editing in lymphocyte development and central tolerance. Nat Rev Immunol, v. 6, n. 10, p. 728-40, Oct 2006. ISSN 1474-1733

NEWTON, R.; PRIYADHARSHINI, B.; TURKA, L. A. Immunometabolism of regulatory T cells. Nat Immunol, v. 17, n. 6, p. 618-25, May 19 2016. ISSN 1529-2916

NGUYEN, H. D. et al. Metabolic reprogramming of alloantigen-activated T cells after hematopoietic cell transplantation. J Clin Invest, v. 126, n. 4, p. 1337-52, Apr 12016. ISSN 1558-8238

O'DONNELL, N. et al. Ogt-Dependent X-Chromosome-Linked Protein Glycosylation Is a Requisite Modification in Somatic Cell Function and Embryo Viability. Molecular and Cellular Biology, v. 24, n. 4, p. 1680-1690, 2004. ISSN 0270-7306.

O'NEILL, L. A.; HARDIE, D. G. Metabolism of inflammation limited by AMPK and pseudo-starvation. Nature, v. 493, n. 7432, p. 346-55, Jan 17 2013. ISSN 1476-4687

OAKHILL, J. S.; SCOTT, J. W.; KEMP, B. E. AMPK functions as an adenylate chargeregulated protein kinase. Trends in Endocrinology \& Metabolism, v. 23, n. 3, p. 125132, 2012. ISSN 10432760.

OKAMURA, N.; SAKAKIBARA, R. A Common Phosphorylation Site for Cyclic AMPdependent Protein Kinase and Protein Kinase $C$ in Human Placental 6-Phosphofructo2-kinase/Fructose-2,6-bisphosphatase. Bioscience, Biotechnology, and Biochemistry, v. 62, n. 10, p. 2039-2042, 2014. ISSN 0916-8451 1347-6947.

OKUDA, Y. et al. IL-6 plays a crucial role in the induction phase of myelin oligodendrocyte glycoprotein $35-55$ induced experimental autoimmune 
encephalomyelitis. Journal of Neuroimmunology, v. 101, n. 2, p. 188-196, 1999. ISSN 01655728.

OUYANG, W. et al. Foxo proteins cooperatively control the differentiation of Foxp3+ regulatory T cells. Nat Immunol, v. 11, n. 7, p. 618-27, Jul 2010. ISSN 1529-2916

PALAZON, A. et al. HIF transcription factors, inflammation, and immunity. Immunity, v. 41, n. 4, p. 518-28, Oct 16 2014. ISSN 1097-4180 (Electronic) 1074-7613

RODRIGUEZ-GARCIA, A. et al. TGF-beta1 targets Smad, p38 MAPK, and PI3K/Akt signaling pathways to induce PFKFB3 gene expression and glycolysis in glioblastoma cells. FEBS J, v. 284, n. 20, p. 3437-3454, Oct 2017. ISSN 1742-4658 (Electronic) $1742-464 X$

RUIZ-GARCÍA, A. et al. Cooperation of Adenosine with Macrophage Toll-4 Receptor Agonists Leads to Increased Glycolytic Flux through the Enhanced Expression ofPFKFB3Gene. Journal of Biological Chemistry, v. 286, n. 22, p. 19247-19258, 2011. ISSN 0021-92581083-351X.

SAKAGUCHI, S. Regulatory T cells: key controllers of immunologic self-tolerance. Cell, v. 101, n. 5, p. 455-8, May 26 2000. ISSN 0092-8674 (Print) 0092-8674

. Naturally arising CD4+ regulatory t cells for immunologic self-tolerance and negative control of immune responses. Annu Rev Immunol, v. 22, p. 531-62, 2004. ISSN 0732-0582

SAKAKIBARA, $R$. et al. Characterization of a human placental fructose-6-phosphate, 2-kinase/fructose-2,6-bisphosphatase. J Biochem, v. 122, n. 1, p. 122-8, Jul 1997. ISSN 0021-924X

SAWANT, D. V.; VIGNALI, D. A. Once a Treg, always a Treg? Immunol Rev, v. 259, n. 1, p. 173-91, May 2014. ISSN 1600-065X (Electronic)

0105-2896

SCHLEICHER, E. D.; WEIGERT, C. Role of the hexosamine biosynthetic pathway in diabetic nephropathy. Kidney Int Suppl, v. 77, p. S13-8, Sep 2000. ISSN 0098-6577

SHARMA, A.; RUDRA, D. Emerging Functions of Regulatory T Cells in Tissue Homeostasis. Frontiers in Immunology, v. 9, 2018. ISSN 1664-3224.

SIMON-MOLAS, $\mathrm{H}$. et al. PI3K-Akt signaling controls PFKFB3 expression during human T-lymphocyte activation. Mol Cell Biochem, Feb 12 2018. ISSN 1573-4919

SIMON-MOLAS, $\mathrm{H}$. et al. PI3K-Akt signaling controls PFKFB3 expression during human T-lymphocyte activation. Molecular and Cellular Biochemistry, v. 448, n. 12, p. 187-197, 2018. ISSN 0300-81771573-4919. 
SUGIURA, A.; RATHMELL, J. C. Metabolic Barriers to T Cell Function in Tumors. J Immunol, v. 200, n. 2, p. 400-407, Jan 15 2018. ISSN 1550-6606 (Electronic) 0022-1767

SUN, C. et al. O-GlcNAcylation: a bridge between glucose and cell differentiation. Journal of Cellular and Molecular Medicine, v. 20, n. 5, p. 769-781, 2016. ISSN 15821838.

SWAMY, M. et al. Glucose and glutamine fuel protein O-GlcNAcylation to control T cell self-renewal and malignancy. Nature Immunology, v. 17, n. 6, p. 712-720, 2016. ISSN 1529-29081529-2916.

TELANG, S. et al. Small molecule inhibition of 6-phosphofructo-2-kinase suppresses t cell activation. J TransI Med, v. 10, p. 95, May 16 2012. ISSN 1479-5876 (Electronic) 1479-5876

TELANG, S. et al. Small molecule inhibition of 6-phosphofructo-2-kinase suppresses $t$ cell activation. Journal of Translational Medicine, v. 10, n. 1, 2012. ISSN 14795876.

TELANG, S. et al. Ras transformation requires metabolic control by 6-phosphofructo2-kinase. Oncogene, v. 25, n. 55, p. 7225-34, Nov 23 2006. ISSN 0950-9232 (Print) 0950-9232

VAN SCHAFTINGEN, E.; HUE, L.; HERS, H. G. Control of the fructose-6phosphate/fructose 1,6-bisphosphate cycle in isolated hepatocytes by glucose and glucagon. Role of a low-molecular-weight stimulator of phosphofructokinase. Biochem J, v. 192, n. 3, p. 887-95, Dec 15 1980. ISSN 0264-6021

VAN SCHAFTINGEN, E. et al. Control of liver 6-phosphofructokinase by fructose 2,6bisphosphate and other effectors. Proc Natl Acad Sci U S A, v. 78, n. 6, p. 3483-6, Jun 1981. ISSN 0027-8424

VYAS, B. et al. Glutamine: fructose-6-phosphate amidotransferase (GFAT): homology modelling and designing of new inhibitors using pharmacophore and docking based hierarchical virtual screening protocol. SAR QSAR Environ Res, v. 24, n. 9, p. 73352, 2013. ISSN 1029-046X

WANG, $R$. et al. The transcription factor Myc controls metabolic reprogramming upon T lymphocyte activation. Immunity, v. 35, n. 6, p. 871-82, Dec 23 2011. ISSN 10974180

WEBER, G. Enzymology of cancer cells (first of two parts). N Engl J Med, v. 296, n. 9, p. 486-92, Mar 3 1977. ISSN 0028-4793 (Print) 0028-4793

WILSON, J. E. Isozymes of mammalian hexokinase: structure, subcellular localization and metabolic function. J Exp Biol, v. 206, n. Pt 12, p. 2049-57, Jun 2003. ISSN $0022-$ 0949 
WINDT, G. J. W.; PEARCE, E. L. Metabolic switching and fuel choice during T-cell differentiation and memory development. Immunological Reviews, v. 249, n. 1, p. 27 42, 2012. ISSN 01052896. 


\section{APÊNDICE}

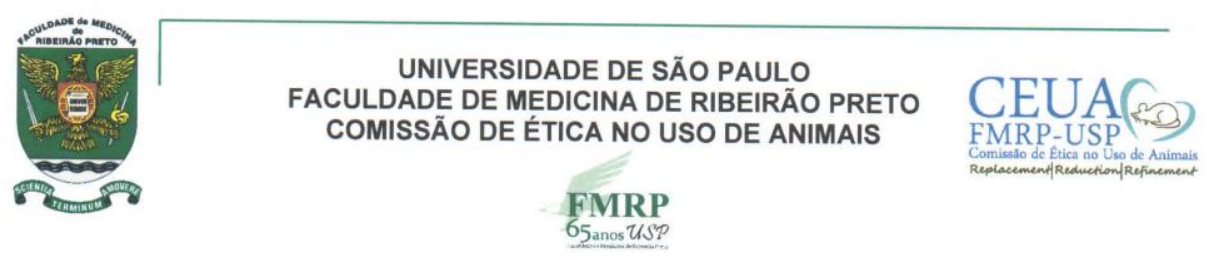

\section{E R T I F I C A D O}

Certificamos que o Protocolo intitulado "Papel da enzima PFKFB-3 na célula T reguladora", registrado com o número 126/2018, sob a responsabilidade do Prof. Dr. José Carlos Farias Alves Filho, envolvendo a produção, manutenção ou utilização de animais pertencentes ao filo Chordata, subfilo Vertebrata (exceto humanos) para fins de pesquisa científica, encontra-se de acordo com os preceitos da Lei $\mathrm{n}^{\circ} 11.794$ de 8 de outubro de 2008, do Decreto ${ }^{\circ} 6.899$ de 15 de julho de 2009 e com as normas editadas pelo Conselho Nacional de Controle de Experimentação Animal (CONCEA), e foi APROVADO pela Comissão de Ética no Uso de Animais da Faculdade de Medicina de Ribeirão Preto da Universidade de São Paulo em reunião de 30 de julho de 2018.

Este Protocolo prevê a utilização de 111 camundongos C57Bl/6 machos pesando 22g oriundos do Serviço de Biotério da Prefeitura do Campus de Ribeirão Preto da Universidade de São Paulo, 36 camundongos FOXp3GFP machos pesando 22g oriundos do Centro de Criação de Camundongos Especiais da Faculdade de Medicina de Ribeirão Preto da Universidade de São Paulo. Vigência da autorização: 30/07/2018 a 20/01/2020.

We certify that the Protocol $n^{\circ} 126 / 2018$, entitled "Role of the PFKFB-3 enzyme in the regulatory $T$ cell", is in accordance with the Ethical Principles in Animal Research adopted by the National Council for the Control of Animal Experimentation (CONCEA) and was approved by the Local Animal Ethical Committee from Ribeirão Preto Medical School of the University of São Paulo in 07/30/2018. This protocol involves the production, maintenance or use of animals from phylum Chordata, subphylum Vertebrata (except humans) for research purposes, and includes the use of 111 male $\mathrm{C} 57 \mathrm{Bl} / 6$ mice weighing $22 \mathrm{~g}$ from the Central Animal House of Ribeirao Preto Medical School, 36 male FOXp3GFP mice weighing 22g from the Breeding Center of Special Mice of Ribeirao Preto Medical School, University of São Paulo. This certificate is valid until 01/20/2020.

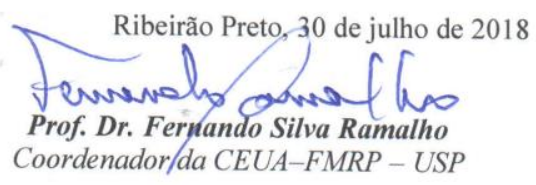

Faculdade de Medicina de Ribeiráo Preto - USP - Av. Bandeirantes, 3900 - Ribeiråo Preto - SP - Brasil -14049-900 - Tel.: (16) 3315-3301 / 3315.3275 - e-mail: ceua @ifmrp. usp.br 